\title{
Cell-scale biophysical determinants of cell competition in epithelia
}

\author{
Daniel Gradeci ${ }^{\dagger 1,2}$, Anna Bove $e^{\dagger 2,3}$, Giulia Vallardi ${ }^{4}$, Alan R. Lowe ${ }^{* 2,4,5}$, Shiladitya \\ Banerjee $^{* 1,5,6}$, Guillaume Charras $* 2,3,5$
}

${ }^{1}$ Department of Physics and Astronomy, University College London, Gower Street, London, WC1E 6BT, UK

${ }^{2}$ London Centre for Nanotechnology, University College London, 17-19 Gordon Street, London, WC1H 0AH, UK

${ }^{3}$ Department of Cell and Developmental Biology, University College London, Gower Street, London, WC1E 6BT, UK

${ }^{4}$ Institute for Structural and Molecular Biology, University College London, Gower Street, London, WC1E 6BT, UK

${ }^{5}$ Institute for the Physics of Living Systems, University College London, Gower Street, London, WC1E 6BT, UK

${ }^{6}$ Department of Physics, Carnegie Mellon University, Pittsburgh, PA 15213, USA

${ }^{\dagger}$ These authors contributed equally

*correspondence: g.charras@ucl.ac.uk, a.lowe@ucl.ac.uk, shiladtb@andrew.cmu.edu

\begin{abstract}
How cells with different genetic makeups compete in tissues is an outstanding question in developmental biology and cancer research. Studies in recent years have revealed that cell competition can either be driven by short-range biochemical signalling or by long-range mechanical stresses in the tissue. To date, cell competition has generally been characterised at the population-scale, leaving the single-cell level mechanisms of competition elusive. Here, we use high time-resolution experimental data to construct a multi-scale agent-based model for epithelial cell competition, and use it to gain a conceptual understanding of the cellular factors that governs competition in cell populations within tissues. We find that a key determinant of mechanical competition is the difference in homeostatic density between winners and losers, while differences in growth rates and tissue organisation did not affect competition end-result. In contrast, the outcome of biochemical competition is strongly influenced by local tissue organisation. Indeed, when loser cells are homogenously mixed with winners at the onset of competition, they are eradicated; however, when they are spatially separated, winner and loser cells coexist. These findings suggest distinct biophysical origins for mechanical and biochemical modes of cell competition.
\end{abstract}




\section{Introduction}

Cell competition is a fitness control mechanism in which less fit cells (the losers) are eliminated from a tissue for optimal survival of the host $[1,2]$. First discovered in the Drosophila wing disc [3], cell competition has since been observed in many other physiological and pathophysiological contexts, especially in embryogenesis [4] and the development of tumours $[5,6]$. While there have been extensive population-scale studies of competition $[7,8]$, the competitive strategies and their underlying mechanisms at the single-cell level remain poorly understood.

Two broad classes of cell competition have been described. Mechanical competition arises because loser cells are more sensitive to crowding than winners [9]. Losers are thought to die cell-autonomously because of increasing overall density and loser cells far from the interface with winners may die $[8,10]$. By contrast, during biochemical competition, signalling occurs at the interface between cell types leading to apoptosis of loser cells in direct contact with winners $[7,11]$. Here, the probability of elimination depends on the extent of contact a loser cell has with the winners $[12,13]$. As a result, perturbations affecting the strength of intercellular adhesions strongly affect the outcome of competition, suggesting that cell mixing is an important factor in biochemical competition [12].

One challenge in understanding cell competition from experimental data is that it takes place over several days, making the tracking of a cell's environment and its eventual fate complex. The emergence of automated long-term microscopy and advanced image analysis for segmentation and cell state recognition enables hypotheses to be formulated regarding the mechanisms of cell elimination [14]. For example, recent work has shown that loser cell death in an experimental model system for mechanical competition is strongly influenced by local cell density as expected, but that, in addition, division of winner cells is favoured in neighbourhoods with many loser cells, something reminiscent of biochemical competition [15]. Therefore, multiple modes of competition may be at play simultaneously and which of these determines the outcome remains unclear.

One way of gaining conceptual understanding into a complex multi-variate biophysical process is through computational or mathematical modelling. While population-scale models of competition based on ordinary or partial differential equations capture the overall behaviour of the tissue $[9,15,16]$, they do not provide insights into the influence of local tissue organisation, mechanics and cell-cell signalling on the outcome of competition. Cell-resolution computational models are well suited for describing how the behaviour of single cells and cellcell interactions lead to population-scale dynamics $[17,18]$. However, cell-scale models of competition have not yet been implemented to test different competitive strategies or investigate the physical and topological parameters that are important in competition. This is partly due to the lack of high-time resolution experimental data to allow a robust comparison of models with experimental evidence as well as challenges in implementing basic biological phenomena thought to be central to competition, such as homeostatic density.

Here we develop a multi-scale agent-based computational model to gain conceptual understanding of the single-cell mechanisms that govern cell competition. Our modelling study is informed by our own experimental work in which we characterized single-cell mechanical competition using automatic annotation of movies lasting up to 4 days [15]. Following analysis, these movies provide the fate and position of all cells over time, allowing for rigorous comparison of simulation to experiments. After calibrating the behaviour of winner and loser 
cells based on movies of pure cell populations, we show that we can replicate competition when the two distinct cell types are mixed and investigate the impact of each interaction and kinetic parameters on the outcome of mechanical cell competition. We then implement a model of biochemical competition based on contact-dependent death that can replicate all current experimental observations and uncover the key parameters influencing its outcome. We find that mechanical competition appears to be controlled by the difference in homeostatic density between cell types, whereas biochemical competition is governed by tissue organisation.

\section{Results}

\section{Experimental pipeline}

In our experiments, we examined competition between wild-type Madin-Darby Canine kidney epithelial cells (winners, $\mathrm{MDCK}^{\mathrm{WT}}$ ) and cells depleted for the polarity protein scribble (losers, $\mathrm{MDCK}^{\text {Scrib}}$ ) [19]. To allow for simple image analysis, each cell type stably expressed a histone marker with a different fluorophore (MDCK ${ }^{\mathrm{WT}}$ : GFP and $\left.\mathrm{MDCK}^{\text {Scrib }}: \mathrm{mRFP}\right)$. Cells were seeded in various ratios of loser: winner cells (10:90, 50:50, 90:10) and imaged for up to $96 \mathrm{~h}$ at 4 minute intervals. Cell segmentation and tracking allowed to determine population measurements (such as the evolution of cell count, the number of mitoses, and the number of apoptoses) as well as cellular-scale measurements (such as local cell density, number of neighbours, identity of neighbours, and cell state) for each cell type [15]. These data provided the metrics to compare simulations to experiments.

\section{A multi-scale agent-based model for cell competition}

To understand the emergence of cell competition, we implemented a multi-scale agent-based model that simulates mechanical interactions between cells and with their underlying substrate (Fig 1A, grey shaded area), and cell-autonomous decisions for growth, mitosis and apoptosis (Fig. 1A, pink shaded area). In contrast to existing computational approaches [20, 21], our model implements the coupling between cellular mechanics and decision-making.

In our simulation, cells are represented using a Cellular Potts Model [22], which enables physical interactions at the cell-cell and cell-substrate interfaces to be simulated (Fig 1A, grey shaded area, Materials and Methods). This implementation was preferred to the less computationally costly vertex model [23], because we compare our model to our in vitro competition experiments [15] that start from a sub-confluent state. In the Potts model, each cell type is assigned an adhesion energy with other cells $\left(\mathrm{J}_{\text {cell-cell }}\right)$, an adhesion energy with the substrate ( $\mathrm{J}_{\text {cell-substrate }}$ ), a preferred area $A_{T}$ (the target area), and a stiffness modulus, $\lambda$. Cells with a lower $\mathbf{J}$ value will adhere more strongly. When more than one cell type is involved, different adhesion energies are set for homotypic adhesion ( $\mathrm{J}_{\text {homotypic }}$ between cells of the same type) and heterotypic adhesion ( $\mathrm{J}_{\text {heterotypic }}$ between cells of different types).

While the balance of forces between adhesion and elasticity determines equilibrium cell shapes, changes in cell size during growth, division and apoptosis are controlled by a second computational layer comprising cellular automata rules (Fig 1A, pink shaded area). It is in this layer that cellular decision-making is implemented at each time-point based on a set of probabilistic rules that we determine from our experimental data (Materials and Methods). We now briefly describe these rules and the calibration of their associated parameters (Fig 2A).

Experimental work has shown that MDCK cells maintain size homeostasis by following an 'adder' mechanism, in which each cell cycle adds a set volume to the cell [24] (Fig 1B). In our model, we increase each cell's target area $A_{T}$ at each time point and cells divide when a threshold 
area had been added since the start of their cell cycle (Fig. S1), calibrated using our experimental measurements of cell cycle time. Above a certain cell density, proliferation ceases - a phenomenon known as contact inhibition of proliferation [25, 26]. Arrest in proliferation is accompanied by a decrease in protein synthesis due to a drop in ribosome assembly and downregulation of the synthesis of cyclins [27]. We incorporated contact inhibition of proliferation (Fig. 1E), such that the increase in a cell's target area $A_{T}$, and consequently division timing, slows down exponentially as the local cell density $\rho$ increases (Materials and Methods). We assume that the effective growth rate of the cell depends on the difference between the actual cell area $A$ and the target area $A_{T}$ as: $d A_{T} / d t=G e^{-k\left(A-A_{T}\right)^{2}}$, where $G$ is the growth rate of isolated cells and $k$ quantifies the sensitivity to contact inhibition.

We implemented two distinct rules for apoptosis for mechanical and biochemical competition (Fig. 1C). (i) Under crowded conditions where mechanical competition is dominant, the probability of apoptosis $p_{\text {apo }}$ increases with local cell density $\rho$ following a sigmoid curve (Fig. S2). Our experimental data suggested that winner cell apoptosis followed the same law as losers but shifted towards higher local densities [15]. (ii) In biochemical competition, experimental data indicates that the probability of apoptosis of loser cells depends on the percentage of their perimeter in contact with the winner cells (heterotypic contact, Fig. S3A) [12]. This was implemented as a Hill function as a function of percentage of perimeter occupied by heterotypic contact (Materials and Methods).

In experiments, cell elimination can also occur within tens of minutes through live cell extrusions $[28,29]$. In our simulations, when a cell's actual area, $A$, dropped below half the average area of all cells in the simulation $\left\langle A_{i}\right\rangle$, the cell was eliminated immediately (Fig. 1D).

Taken together, the combination of cellular mechanics and decision-making strategies provides a multi-scale agent-based model to investigate how the interplay between short-range and longrange competitive interactions determine tissue composition. As many parameters are used to describe each cell type's behaviour, careful calibration of the simulations based on experimental data is necessary to restrict the parameter space sufficiently to obtain informative behaviours (Fig. 2).

\section{Growth and homeostasis of pure cell populations}

To validate the predictive power of our model, we first simulated homeostasis in pure cell populations of winner and loser cells undergoing proliferation and apoptosis. To calibrate our model parameters (Fig 2A), we compared simulations to experiments on the basis of the temporal evolution of cell count and cell density (Fig 2C). In addition, as experimental and theoretical work has shown that cell organisation in monolayers can be described by the distribution of number of neighbours each cell possesses [30] and their area relative to the population mean [31], we also used these cell-scale metrics for confluent epithelia (Fig $\mathbf{2 A}, \mathbf{C}$, 3C-H, Fig S4).

At the start of our experiments, many isolated cells can be observed ( $t=0 h$, Fig 3B, Fig S5A). $\mathrm{MDCK}^{\text {Scrib }}$ cells spread markedly more than $\mathrm{MDCK}^{\mathrm{WT}}$ (Fig S5B, D, compare MDCK ${ }^{\mathrm{WT}}$ in Movie S2 to MDCK $^{\text {Scrib }}$ in Movie S3), consistent with [8]. Interestingly, in mixed populations dominated by WT cells, MDCK ${ }^{\text {Scrib }}$ cell area diminished compared to pure populations even prior to confluence (Fig S5C-E). We used these measurements to parametrise $A_{T}$. Transcriptomic data comparing both cell types indicates that $\mathrm{MDCK}^{\text {Scrib }}$ do not express more integrins than $\mathrm{MDCK}^{\mathrm{WT}}$ [8]. Therefore, we assigned the same value of $J_{\text {Substrate }}$ to both cell types. 
The growth rate $\mathrm{G}$ was parameterised based on the measured distribution of cell cycle durations prior to confluence [15], which showed that losers grew significantly slower than winners (mean cell cycle times: $\mathrm{MDCK}^{\mathrm{Scrib}} \sim 21.6 \mathrm{~h}$ vs $\left.\mathrm{MDCK}^{\mathrm{WT}} \sim 18 \mathrm{~h}\right)$. Therefore, we assigned a smaller $\mathrm{G}$ to losers than to winners.

After confluence, cell shape is controlled by the interplay between intercellular adhesion energy $J_{\text {homotypic }}$ and the stiffness modulus $\lambda$. The value of $J_{\text {homotypic }}$ was adjusted such that, at confluence, the distributions in apical area, number of neighbours, and area relative to the population mean matched experiments (Fig S4A-B), as done by others [31]. An accurate replication of sidedness of cells is particularly important for simulating biochemical competition because the probability of apoptosis of loser cells is linked to the fraction of their perimeter contacting winner cells [12]. Previous experimental work showed that, in competition experiments, the area of losers was significantly smaller than winners $[8,15]$. Therefore, we assigned losers a smaller value of $\lambda$ than winners.

The strength of contact inhibition, $k$ (Materials and Methods), was chosen such that the cell density at long time scales in simulations reached a plateau that matched the one observed in experiments (Fig 3D, G).

In mechanical competition experiments, loser cells undergo apoptosis when they are in crowded environments. Therefore, we implemented a relationship between probability of apoptosis per cell per unit time ( $\mathrm{p}_{\text {apo }}$ ) and the local cell density $\rho$ derived by fitting our experimental data with a sigmoid function (Methods, Fig S2A, [15]). The local cell density $\rho$ was defined as the inverse of the sum of area of the cell of interest and its first neighbours (Methods, Fig S2B). While papo saturates at high densities for loser cells, experimental data was not available for the highest densities for winner cells (data points, Fig S2A). Therefore, we assumed that the maximum of $\mathrm{p}_{\text {apo }}$ was the same for winner and loser cells (Fig S2A).

When the simulations were initialised with the calibrated parameters and the same initial cell number as in experiments (Fig 2A), cell count and density in the simulations quantitatively reproduced our experimental observations (Fig. 3A-B, Fig. S2, Movie S1 and S2). MDCK WT cell count increased for $\sim 70 \mathrm{~h}$ before reaching a plateau at a normalised cell count of 5.5, indicative of homeostasis (Fig. 3C). The temporal evolution of the average local cell density and the distribution of number of neighbours at confluence were also faithfully replicated by our simulations (Fig. 3D-E). Similarly, our parametrisation of MDCK $^{\text {Scrib }}$ accurately replicated the temporal evolution of cell count and density, as well as the distribution of the number of cell neighbours (Fig. 3F-H, Movie S4). In particular, the loser cell count and density stayed fairly constant throughout the simulation and experiment.

\section{Model epithelia maintain a homeostatic density}

The maintenance of an intact barrier between the internal and the external environment is a key function of epithelia. This necessitates exact balancing of the number of cell deaths and divisions. Failure to do so results in hyperplasia, an early marker of cancer development. Recent work has revealed that epithelia possess a preferred density (a homeostatic density) to which they return following perturbation [28, 32, 33]. In experiments, cells were grown to confluence on stretchable substrates and subjected to a step deformation in one axis. When deformation increased cellular apical area, cells resumed division [33], while a decrease in apical area resulted in live cell extrusion and apoptosis [28]. Therefore, the existence of a homeostatic density is an essential property of epithelia that relates to their sensitivity to crowding - a key factor in mechanical competition. However, current models of epithelia do not implement this. 
In our model, we implemented two mechanisms shown experimentally to decrease cell density: cell extrusions and density-dependent apoptoses (Fig 1C, D, Methods). We simulated the response of a confluent epithelium to a sudden $30 \%$ increase in homeostatic density. In experiments on confluent $\mathrm{MDCK}^{\mathrm{WT}}$ epithelia [28], the sudden increase in crowding was followed by a gradual decrease in cell density resulting from a combination of apoptoses and live cell extrusion, before returning to the initial homeostatic density after $\sim 6 \mathrm{~h}$ (green data points, Fig. 4).

In our simulations, we allowed $\mathrm{MDCK}^{\mathrm{WT}}$ cells to reach their homeostatic density before suddenly increasing the cell density by an amount similar to experiments. Following this, cell density decreased gradually over a period of $6 \mathrm{~h}$ with dynamics similar to those determined experimentally (blue dots, Fig 4B). Thus, our model implementation and parametrisation replicate the return to homeostasis of pure populations of $\mathrm{MDCK}^{\mathrm{WT}}$ cells. As the relationship between $p_{\text {apo }}$ and $\rho$ was fitted using the data from our competition experiments, this also raises the possibility that cell apoptosis in response to crowding is a cell-autonomous process rather than specific to cell competition.

\section{Density mediated apoptosis is sufficient to explain mechanical competition}

Our experimental work indicated that, in competitions between $\mathrm{MDCK}^{\mathrm{WT}}$ and $\mathrm{MDCK}^{\mathrm{Scrib}}$, two processes might be at play, a density-dependent apoptosis of $\mathrm{MDCK}^{\text {Scrib }}$ and an upregulation of division of $\mathrm{MDCK}^{\mathrm{WT}}$ in $\mathrm{MDCK}^{\mathrm{Scrib}}$-dominated neighbourhoods [15]. The former is central to mechanical competition, while the latter implies that contact between cell types controls division rate. To determine which process was dominant, we tested whether cell-type differences in density-mediated apoptosis alone were sufficient to explain competition.

We used our model of winner and loser cells with different sensitivities to crowding parametrised from experiments on pure cell populations (Fig 3). We initialised our simulations by seeding a 90:10 winner-to-loser cell ratio, as in experiments. Our simulations were able to quantitatively reproduce the experimental data for competition dynamics, with no further adjustment in parameters (Table S1). As in the experiments (Fig 5B), simulated winner cells (green) rapidly proliferated while loser cell numbers (red) increased weakly until $\sim 50 \mathrm{~h}$ before diminishing (Fig. 5A-B, Movie S4 and S5). Furthermore, the evolution of cell count was quantitatively replicated over the entire duration of the experiment for both winner and loser cells (Fig. 5C). As in experiments [15], the greater increase in winner cell count was due to a combination of more frequent division (Fig S4C) and less frequent death (Fig S4D) than in loser cells. One of the most striking features of experimental data is that the local density of loser cells increases dramatically compared to pure populations ( $\sim 5$ fold increase, compare magenta curve Fig. 5D to the magenta curve in pure populations, Fig. 3G), while the local density of winner cells follows the same trend as in pure populations (compare green curve Fig. 5D to green curve in pure populations Fig. 3D) [15]. The sharp increase in local density of loser cells is replicated in our simulations (black curve, Fig 5D) and likely arises from their lower stiffness modulus, $\lambda$. Previous reports show that an increased local density of loser cells is accompanied by an increase in their height [8], suggesting that $\lambda$ could be interpreted as an outof-plane deformability modulus. Overall, differences in density-dependent apoptosis alone are sufficient to replicate the evolution of cell count and density observed in competition between $\mathrm{MDCK}^{\mathrm{WT}}$ and $\mathrm{MDCK}^{\mathrm{Scrib}}$ [15], suggesting that mechanical competition represents the dominant mechanism of population change in these experiments.

\section{Differences in homeostatic density and cell stiffness control the outcome of mechanical cell competition}


To understand the mechanistic origin of density-mediated cell competition, we varied the

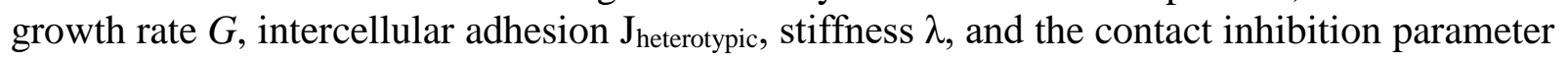
$k$ for the individual cell types starting from an initial set of values that gave rise to mechanical competition (Table S2). We reasoned that, in a competition setting, the values of each parameter in one cell type relative to the other were likely more important than their absolute values. Therefore, we varied each parameter in only one of the two cell types.

We first varied the growth rate $G$ of loser cells (Table S2). We found that $G$ controlled the time required for elimination and the peak loser cell count but did not affect the outcome of competition with losers being eliminated for all growth rates examined (Fig. S6C-D).

Second, we varied the heterotypic adhesion energy, $\mathrm{J}_{\text {heterotypic }}$, between the winners and the losers between $\pm 50 \%$ of the value of the homotypic adhesion $\mathrm{J}_{\text {homotypic }}$ (Table $\mathbf{S 2}$ ). When $\mathrm{J}_{\text {heterotypic }}$ is larger than $\mathbf{J}_{\text {homotypic, }}$, cells preferentially adhere to cells of their own type. In our simulations, $\mathbf{J}_{\text {heterotypic }}$ controlled the kinetics of competition but did not change its outcome (Fig S6E). Note that varying $\mathbf{J}_{\text {homotypic }}$ in one of the cell types only would have similar effects to a variation in $\mathrm{J}_{\text {heterotypic. }}$

In our simulations, sensitivity to contact inhibition $k$ was chosen to be the same for both cell types and it constrains how far cells can deviate from their target area $A_{T}$ before they quiesce (Materials and Methods, Table S2). In pure winner cell populations, homeostatic density $(H D)$ decreased with increasing contact inhibition (Fig. 6A), where homeostatic density is defined as the average local density of a cell type post-confluence. However, this effect was not observed in pure loser populations (Fig. 6A) because their probability of apoptosis is high even for densities below the homeostatic density dictated by $k$ (Fig. S2A). Indeed, under normal growth conditions, we predict that loser cells never reach densities where contact inhibition becomes active. In all cases, the homeostatic density of winner cells was higher than in loser cells but the difference in homeostatic density, $\triangle H D$, decreased with increasing $k$ (Fig. 6A). Thus, in winner cells, homeostatic density is controlled by the contact inhibition parameter $k$, while in loser cells it is controlled by density-dependent apoptosis (Fig. S2A).

When we varied the homeostatic density of the winner cells (by changing $k$, Table S2), we found that, after $80 \mathrm{~h}$, loser cells were completely eliminated for high values of winner cell homeostatic density but they survived when winner homeostatic density was lower (Fig. 6B-C, E). In addition, the time required for elimination of $50 \%$ of loser cells increased with decreasing difference in homeostatic density (Fig. 6A, F). Therefore, the difference in homeostatic density, $\triangle H D$, between the winner and loser cells governs the kinetics and the outcome of mechanical competition (Fig. 6A, C, F).

As in our initial parameterisation the winner cells have a higher stiffness $\lambda$, the loser cells are compressed by the winners in competition. As a result, the average density of loser cells is larger than that of winners, leading to increased apoptosis. To determine the impact of $\lambda$ on competition, we varied the loser cell stiffness while maintaining winner cell stiffness constant. When the relative stiffness parameter $\Lambda=\lambda_{\text {loser }} / \lambda_{\text {winner }}$ was larger than 1 , loser cells were eliminated (Fig. S6A). By contrast, when $\Lambda$ was equal to or higher than 1 , loser cells survived (Fig. S6A, Fig. 6D). Akin to $\Delta H D$, changes in the ratio of winner-to-loser cell stiffness altered the kinetics of competition (Fig. 6D). These results are consistent with experiments showing that competition is decreased in the presence of an inhibitor of Rho-kinase (Y27632) that reduces cell contractility in both populations [8]. 
When $\triangle H D$ was high or $\Lambda$ was larger than 1 , the change in competition outcome occurred because of a decrease in the local density of loser cells in mixed populations, which in turn led to decreased apoptosis. However, winners have an extra competitive edge because when free space becomes available due to cell death or cell area compressibility, they take advantage of the free space due to faster growth using a squeeze and take or a kill and take tactic [14].

\section{Tissue organisation predicts the outcome of biochemical competition}

In addition to mechanical competition, our simulation can also be used to gain mechanistic insights into biochemical competition. Recent work has shown that, during biochemical competition, apoptosis in loser cells is governed by the extent of their contact with winner cells [10] and that perturbations that increase mixing between cell types increase competition [12].

To study biochemical competition in isolation from any mechanical effect, we assumed that both cell types have identical stiffnesses $\lambda$, equal sensitivities to contact inhibition $k$, and high but equal homeostatic densities (Table S3). In both cell types, we modelled the dependency of apoptosis on the proportion of cell perimeter $p$ engaged in heterotypic contact by using a Hill function parameterised by a steepness $S$ and an amplitude $p_{a p o, \max }$ :

$p_{\text {apo }}(p)=\frac{p_{a p o, \max } p^{n}}{\left(S^{n}+p^{n}\right)}$, where $n$ is the Hill coefficient $($ Fig. S3A $)$.

When $S$ decreases, the probability of apoptosis increases rapidly with the extent of heterotypic contact (Fig. S3A). For winner cells, we chose a low $p_{\text {apo,max }}$ and high $S$ because we do not expect their apoptosis to show sensitivity to contact with loser cells. In contrast, for loser cells, we chose $p_{a p o, \max }$ to be ten-fold higher than in winners, giving an amplitude similar to the maximal probability of apoptosis observed in losers during mechanical competition (Fig. S3A, S2A). To investigate biochemical competition, we varied parameters modulating contact between cells (the heterotypic adhesion $J_{\text {heterotypic }}$ ), apoptosis of losers (the Hill function parameters $p_{a p o, \max }$ and $S$ of loser cells), as well as tissue organisation.

First, we assumed a homogenous seeding of each cell type with a 50:50 ratio between winners and losers. Competition depends on the relative value of the probability of apoptosis $p_{a p o}$ in winners and losers as a function of the fraction of their perimeter $p$ in heterotypic contact (Fig 1C, right). Therefore, varying $p_{a p o, \max }$ or $S$ has a qualitatively similar overall effect on competition. We examined the dependency of competition outcome on $S_{\text {Loser }}$ with $S_{\text {Winner }}$, $p_{\text {apo max,winner }}$, and $p_{\text {apo max,loser }}$ fixed (Table S3). For all values of $S_{\text {Loser }}$, loser cells first increased in number until overall confluence at $\sim 60 \mathrm{~h}$, before decreasing after that (Fig S3B). When $S_{\text {Loser }}$ was low, losers were eliminated because $p_{\text {apo }}$ for losers was higher than for winners for all heterotypic contact extents (Fig. S3B, C, Movie S6), whereas when $S_{\text {Loser }}$ was high, winners and losers had comparable $p_{\text {apo }}$ when in heterotypic contact, leading to coexistence because no competition took place (Fig. S3C).

Next, we investigated the dependency of cell competition on initial seeding conditions for values of $S_{\text {Loser }}$ that gave rise to competition $\left(S_{\text {Loser }}=0.3, S_{\text {Winner }}=0.5\right.$, Table S3). We examined three different initial seeding conditions: fully mixed (Fig. 7A, middle column), partially sorted with loser cells grouped into a few colonies (Fig. 7B, middle column, Movies S7-9), and fully sorted with loser cells and winner cells occupying opposite sides of the field of view (Fig. 7C, middle column, Movies S10). Strikingly, loser cells were always eliminated in mechanical competition (Fig. 7A-C, left hand column, Fig. 7E), consistent with our experimental observations in fully mixed (Fig 5B) and partially sorted conditions (Fig S8A-C, Movie S9). In 
contrast, the outcome of competition was strongly dependent on initial seeding conditions in biochemical competition (Fig. 7A-C, right hand column, Fig. 7D). Indeed, whereas loser cells were eliminated for fully mixed seeding, they coexisted with winner cells for partially and fully sorted seedings. This suggests that biochemical competition is sensitive to tissue organisation. To quantitatively compare tissue organisations, we computed the evolution of mixing entropy, a measure of local tissue organisation, in each competition (Materials and Methods). We found that, when cells reached confluence, entropy of mixing was highest in the fully mixed seeding and lowest in the fully sorted seeding (Fig. 7F). In the fully mixed and partially sorted seedings, mixing entropy decreased after overall confluence as the competition progressed, whereas for fully sorted, mixing entropy stayed constant because no competition took place (Fig. 7F). Loser colony size and geometry therefore determine the impact of biochemical competition. Indeed, when colonies of loser cells have a small radius as in fully mixed conditions (Fig 7A, Fig S7A), they are eliminated because each cell at the colony interface comes into contact with several winner cells, leading to increased competition. In contrast, in the fully sorted conditions (Fig 7C), the interface between loser and winner cells has a low curvature (Fig S7A) such that loser cells do not contact a sufficient number of winner cells to be eliminated.

In contrast to mechanical competition, we found that the outcome of biochemical competition was controlled by tissue organisation and the intermixing of cells. The extent of cell intermixing is likely affected by the relative magnitude of heterotypic versus homotypic intercellular adhesion energy. Therefore, we examined how changes in heterotypic adhesion, $J_{\text {heterotypic }}$, affected the outcome of competition for a fixed value of $J_{\text {homotypic. }}$ In the Potts model, $J$ represents a surface energy which is the difference between the surface tension and adhesion. Therefore, when $J$ is high, intercellular adhesion is low. We found that the final normalised loser cell count decreased with decreasing $J_{\text {heterotypic }}$ in fully mixed and partially sorted tissue organisation (Fig. S7B,C). This is because for low $J_{\text {heterotypic }}$, cell intermixing is favoured and winner cells can invade colonies of loser cells (Fig. S7B-D), consistent with experimental observations [12]. However, in the fully sorted configuration, where the interface between the two cell types is minimal (Fig. 7C, F), changes in $J_{\text {heterotypic }}$ only have a weak effect (Fig. S7D). Thus, the outcome of biochemical competition was sensitive to changes in parameters that affected tissue organisation, such as the relative magnitude of homotypic and heterotypic adhesion energy. In summary, our simple implementation of biochemical competition was sufficient to qualitatively reproduce current experimental observations, although the precise experimental curves relating probability of apoptosis to extent of heterotypic contact remain to be accurately determined experimentally.

\section{Discussion}

In this study, we developed a multi-scale agent-based simulation that allows investigation of the interplay between physical cell interactions and probabilistic decision-making rules in deciding the outcome of cell competition. After parametrisation using high temporal resolution experimental data, our model enabled us to identify the physical and geometrical parameters that influence the outcome of mechanical and biochemical cell competition. Our analysis reveals that the outcome of biochemical competition is governed by tissue organisation and parameters affecting it, whereas the outcome of mechanical competition is controlled by the difference in homeostatic density of the two cell types together with energetic parameters.

Calibration of our model parameters separately for pure populations of winner and loser cells allowed us to quantitatively reproduce the experimentally measured kinetics of cell proliferation, mechanics of tissue homeostasis, as well as the topology of tissue organisation. 
Winners and losers differed in their stiffness $\lambda$, their growth rates $G$, and their probability of apoptosis as a function of density. The latter is directly measured in our experiments [15] and is consistent with the increased sensitivity to crowding in loser cells due to interplay between stress pathways [8,34]. Our simulations showed that the growth rate $G$ controls the kinetics of competition but not its outcome. Overall, only two parameters governed the outcome of mechanical competition: the stiffness $\lambda$, and the sensitivity to contact inhibition quantified by the parameter $k$.

The contact inhibition parameter $k$ regulates the rate of cell growth and proliferation postconfluence (Materials and Methods). In winner cells, this controls homeostatic density, which is lower for high contact inhibition, $k$. However, $k$ does not control homeostatic density in loser cells, due to their increased probability of apoptosis under even moderate crowding conditions. As a result, when $k$ is increased, the difference in homeostatic density between the winners and losers, $\triangle H D$, decreases. This slows the kinetics of mechanical competition, eventually stopping it. Thus, our simulations predict that $\triangle H D$, which is related to the difference in homeostatic density [35], is a good predictor for the outcome of mechanical competition and therefore that perturbing the molecular mechanisms that participate in setting cellular homeostatic density should alter the outcome of competition.

Our model parametrisation based on experimental data suggests that loser cells are typically more compressible (or softer) than winners. As a consequence, in competition assays, loser cells tend to decrease their apical areas more than winners after confluence [8]. This higher local density, together with losers' higher sensitivity to crowding, results in preferential elimination of loser cells. Conversely, when losers are stiffer than winners, their local density does not increase dramatically and they survive. Thus, the relative stiffness parameter $\Lambda$ emerges as a key control parameter for mechanical competition. Loser cells tend to be eliminated if $\Lambda<1$, whereas they survive for $\Lambda>1$. Although by convention $\lambda$ is referred to as an area expansion modulus, cells are three-dimensional objects and their volume is tightly regulated even when subjected to mechanical deformations [36, 37]. Thus, the decrease in apical area of loser cells in competition implies a concomitant increase in their height, consistent with experimental observations [8]. Therefore, $\lambda$ could be interpreted as a height elastic modulus that may emerge from the ratio of apical to lateral contractility that governs the height of epithelial cells in $3 \mathrm{D}$ vertex models [38]. Overall, both contact inhibition of proliferation and planar cell compressibility altered the outcome of mechanical competition by changing the local density attained by the loser cells. Thus, mechanical competition appears to be primarily regulated by parameters controlling the compressional mechanical energy stored in the system. Finally, our simulations suggest that the interaction between MDCK $^{\mathrm{WT}}$ and $\mathrm{MDCK}^{\text {Scrib }}$ cells in our experiments can be entirely explained by mechanical competition alone despite suggestions that biochemical competition may play a role [15].

Biochemical competition depends on the proportion of heterotypic contact between losers and winners. As a result, the outcome of biochemical condition strongly depends on tissue organisation but is not affected by changes in cell compressibility or contact inhibition. Instead, two parameters controlled the outcome of biochemical competition: the heterotypic contact energy and the initial organisation of the tissue. Indeed, tissue organisations with greater mixing between the cell types resulted in increased elimination of the loser cells (Fig. 7). This arises as a natural consequence of the probability of apoptosis of loser cells depending on the extent of heterotypic contact. In other words, competition depends on the extent of cell intermixing. Consistent with this, when the heterotypic contact energy was lower than the homotypic contact 
energy, this led to more mixing between cell types and more cell competition. Interestingly, experimental evidence has revealed that perturbations that promote cohesion of losers protect against elimination, while those that promote intercalation of winners and losers promote greater loser elimination [12]. In biochemical competition, our simulations suggest the existence of a critical colony radius necessary for survival that depends strongly on the shape of the function relating the probability of apoptosis to fraction of perimeter in heterotypic contact (Fig. S3, S7A). While cells did not possess high motility in our simulations, we would expect this to affect the outcome of biochemical competition, as motility would increase cell intermixing.

In summary, our study revealed that mechanical competition is governed by factors that reduce the stored mechanical energy in the system, while biochemical competition is favoured by factors that increase cell intermixing. Conversely, mechanical competition was not affected by tissue organisation, whereas biochemical competition was not sensitive to parameters that changed the stored mechanical energy of the tissue. 


\section{Materials and Methods}

Cellular Potts model. The cellular Potts model is implemented in Compucell3D [39]. We chose a 2D lattice-based model, where cells are composed of a collection of lattice sites (pixels). Cells interact at their interfaces through pre-defined adhesion energies and several different cell types can be implemented. Each cell is then given attributes characterising their mechanical properties. For example, each cell is assigned a cell type $\tau$, which in turn has some value of surface contact energy $J$ with other cell types and the substrate. Cells are also assigned a target area $A_{T}$ and an area expansion modulus $\lambda$, which are important in the implementation of growth and division dynamics. In addition, we also incorporate active cell motility. The free energy of the system is given by the Hamiltonian $H$ :

$$
\begin{gathered}
H=\sum_{<i, j>} J\left[\tau\left(\sigma_{i j}^{k}\right), \tau\left(\sigma_{i^{\prime} j^{\prime}}\right)\right]\left(1-\delta_{m}\left(\sigma_{i j}^{k}, \sigma_{i^{\prime} j^{\prime}}\right)\right)+\lambda \sum_{\sigma}\left(A\left(\sigma^{k}\right)-A_{T}\left(\sigma^{k}\right)\right)^{2} \Theta(\tau) \\
+\lambda_{m} \sum_{\sigma} \widehat{m}(\sigma, t) . \hat{s}
\end{gathered}
$$

where the first term describes the interaction of lattice sites due to the adhesion energy between the cell types or between cells and the substrate. The coefficient $J$ is the surface energy between cell type $\tau$ of the target lattice site $\sigma^{k}$ and the cell type $\tau\left(\sigma_{i^{\prime} j^{\prime}}\right)$ of its nearest neighbour lattice points. By convention, for free space $\tau=0$. From a biological perspective, $J$ is the difference between the surface tension and intercellular adhesion. Therefore, higher $J$ implies lower intercellular adhesion. The multiplicative term $\left(1-\delta_{m}\left(\sigma_{i j}^{k}, \sigma_{i^{\prime} j^{\prime}}\right)\right)$ prevents cells from interacting energetically with themselves, where:

$$
\delta_{i j}= \begin{cases}1, & \sigma_{i j}^{k}=\sigma_{i^{\prime} j^{\prime}}, \\ 0, & \sigma_{i j}^{k} \neq \sigma_{i^{\prime} j^{\prime}} .\end{cases}
$$

The second term in the Hamiltonian describes an additional energy cost due to deviation of the actual area $A(\sigma)$ of a cell from its target area $A_{T}(\sigma)$, specific to each cell type. The coefficient $\lambda$ represents the area expansion modulus in $2 \mathrm{D}$, which is related to planar cell stiffness or the ratio between apical and lateral contractility that control cell height. We introduce the term $\Theta(\tau)$ to treat the free space pixels differently from pixels belonging to cells. In contrast to cells, the free space does not have a target area, and hence no associated mechanical energy.

$$
\Theta_{\tau}= \begin{cases}0, & \tau\left(\sigma_{i j}^{k}\right)=0(\text { free space }), \\ 1, & \text { otherwise } .\end{cases}
$$

The final term in the Hamiltonian assigns active motility to the cells along a random unit vector $\widehat{m}$ [40]. Here, $\hat{s}$ is the spin flip direction between the lattice site in question and one of its neighbouring lattice sites.

Model parametrisation. To describe epithelial cell dynamics using the Potts model, we parametrised it using our experimental data [15]. For simplicity, we chose the same length-scale for pixels in our simulation as in our experimental images of competition experiments. The lattice size and cell sizes are chosen to match the experimental data. The lattice is chosen to be $1200 \times 1600$ pixels, where each pixel is $0.33 \times 0.33 \mu \mathrm{m}^{2}$. 
The target area and stiffness of each cell type were determined based on the average cell areas measured from cells isolated from one another in brightfield images (Fig S5).

A conversion between experimental time and computational time was derived empirically by comparing the mean squared displacements of cells in experiments with those in the simulations. We found that 10 Monte Carlo time steps (MCS) represented 1 frame of a timelapse movie in our experiments (4 min).

Cell growth and division. The agent-based part of the model requires the introduction of cellular behaviour in the form of probabilistic rules for cell growth, division, extrusion, and apoptosis. In our simulations, cells grow linearly by increasing their target areas at a constant rate. The cell growth rate $\mathrm{G}$ was chosen to replicate the average cell doubling time measured in experiments [15]. In line with recent experimental work [24], we assume that MDCK cells follow an "adder" mechanism for cell size control, such that cells divide along their major axis once a threshold volume $\Delta A_{\text {tot }}$ has been added (Fig S1). In our simulations, the added cell volume at each time point was a random value distributed around the mean experimental value $\mathrm{G}$, so as to capture cell-to-cell variability. When the simulation was initialised, cell areas had a homogenous distribution to mimic a uniform probability for cells of being in any given stage of their cell cycle at the start of experiments.

Contact inhibition of proliferation. In our simulations, cells possess a target area, $A_{T}$, which they would occupy if they had no neighbours, and an actual area, $A$, which they currently occupy. As $A_{T}$ increases at each time step due to cell growth, the difference between their target and actual area $A$ increases. If this difference becomes too large, the second term of the Hamiltonian dominates, leading to energetically unfavourable swaps and a collapse of the network. To mimic reduced protein synthesis reported due to contact inhibition of proliferation [27], we assume that the effective growth rate depends on the difference between $A$ and $A_{T}$ :

$$
\frac{d A_{T}}{d t}=G e^{-k\left(A-A_{T}\right)^{2}}
$$

where $G$ is the growth rate for cells with no neighbours, $A_{T}$ the target cell area, $A$ the actual area, and $k$ quantifies the sensitivity to contact inhibition. $k$ parametrises how much deviation can be tolerated between the target area and current cell area before growth stalls. Note that this condition is applied iteratively at every frame for each cell, such that, when free space becomes available, growth can immediately resume nearby.

Apoptosis due to competition. In crowded conditions such as those present in mechanical competition, the probability of apoptosis increases with local cell density [8, 15, 28]. To implement this, each cell was assigned a probability of apoptosis $p_{a p o}$ at each time step that depended on its local cell density $\rho$. In our simulation, $\rho$ was defined as the sum of inverse of areas of the cell of interest $\sigma^{k}$ and its first neighbours $\sigma^{i}: \rho\left(\sigma^{k}\right)=\frac{1}{A\left(\sigma^{k}\right)}+\sum_{i=1}^{n} \frac{1}{A\left(\sigma^{i}\right)}(\mathbf{F i g} \mathbf{S} 2 \mathbf{B})$. Based on our experimental data, we decided to describe the relationship between $p_{\text {apo }}$ and $\rho$ as: $p_{a p o}(\rho)=\frac{p_{a p o, m a x}}{\left(1+e^{-\alpha\left(\rho-\rho_{1 / 2}\right)}\right)}($ Fig. S2A). papo,max was fixed to be the same for both populations and $\rho_{1 / 2}$ was determined for each population separately based on experimental data [15].

In biochemical competition, apoptosis occurs when loser cells are in direct contact with winner cells. Recent work has shown that in Drosophila, the probability of apoptosis of loser cells depends on the percentage of the perimeter in contact with the winner cells [12]. Following this, 
we chose to implement the probability of apoptosis as a sigmoid function (Hill function) following the relationship $p_{a p o}(p)=p_{a p o, \max } p^{n} /\left(S^{n}+p^{n}\right)$, where $p$ is the percentage of perimeter in heterotypic contact, $n$ is the Hill coefficient, $p_{a p o, \max }$ is the maximum probability, and $S$ is the steepness. We chose a maximum probability $p_{a p o, \max }$ of death per frame similar to that encountered in mechanical competition and a Hill coefficient $n=3$ (Fig. S3A). This is justified by the fact that mechanical and biochemical competition take place over comparable durations in MDCK cells 2-4 days [41, 42]. For both mechanical and biochemical competition, the execution of apoptosis was implemented by setting the target area $A_{T}$ of the cell to zero and area expansion modulus $\lambda$ to 2 . This allows for a quick but not instantaneous decrease of the cell area until the cell is completely removed.

Live extrusion of cells. Under conditions where the local cell density increases rapidly, live cells can be extruded from monolayers, likely because they have insufficient adhesion with the substrate to remain in the tissue [28, 29] (Fig. 1D). We assumed that cells underwent live extrusion when their area dropped below half of the average cell area in the simulation at that time point: $A_{i} \leq\langle A\rangle / 2$. Once this occurs, the cell is eliminated immediately from the tissue. Unlike apoptosis, cell elimination via extrusion is implemented as an instantaneous deletion of the qualifying cell from the lattice to reflect the faster rate of extrusions compared to programmed cell death.

Acquisition and analysis of experimental data. All simulated data for mechanical competition were compared quantitatively to experiments acquired in [15] or performed specifically for this publication. Methods for cell culture, image acquisition, segmentation, and analysis are described in detail in [15]. Briefly, MDCK wild type cells $\left(\mathrm{MDCK}^{\mathrm{WT}}\right)$ were winners in these competitions and their nuclei were labelled with H2B-GFP, while MDCK scribble knock down cells $\left(\mathrm{MDCK}^{\mathrm{Scrib}}\right.$, described in [19]) were the losers and labelled with H2B- RFP [15]. MDCK $^{\text {Scrib }}$ cells conditionally expressed an shRNA targeting scribble that could be induced by addition of doxycycline to the culture medium. All cell lines were regularly tested for mycoplasma infection and were found to be negative (MycoAlert Plus Detection Kit, Lonza, LT07-710).

$\mathrm{MDCK}^{\mathrm{WT}}$ cells were grown in DMEM (Thermo-Fisher) supplemented with $10 \%$ fetal bovine serum (Sigma-Aldrich), HEPES buffer (Sigma-Aldrich), and 1\% penicillin/streptomycin in a humidified incubator at $37^{\circ} \mathrm{C}$ with $5 \% \mathrm{CO} 2 . \mathrm{MDCK}^{\mathrm{Scrib}}$ cells were cultured as MDCK ${ }^{\mathrm{WT}}$, except that we included tetracycline-free bovine serum (Clontech, 631106) to supplement the culture medium. To induce expression of scribble shRNA, doxycycline (Sigma-Aldrich, D9891) was added to the medium at a final concentration of $1 \mu \mathrm{g} / \mathrm{ml}$.

For competition assays, winner and loser cells were seeded in the chosen proportion to reach an overall density of 0.07 cells per $100 \mu \mathrm{m}^{2}$ and left to adhere for 2 hours. Cells were then imaged every 4 minutes for 4 days using a custom built incubator microscope and the appropriate wavelengths [15]. Movies were then automatically analysed to track the position, state, and lineage of the cells using deep-learning based image classification, and single-cell tracking, as detailed in [15]. Single cell tracking was performed using bTrack (github.com/quantumjot/BayesianTracker). Cell neighbours are determined using a Voronoi tessellation dual to the Delaunay triangulation of nuclei. Knock-down of scribble was induced $48 \mathrm{~h}$ before the beginning of the experiment to ensure complete depletion.

For experiments examining cell competition in partially sorted conditions, we first seeded the 
same number of $\mathrm{MDCK}^{\text {Scrib }}$ cells as in 90:10 competitions and cultured them for $48 \mathrm{~h}$ without doxycycline until they formed colonies. Then, we added the number of MDCK $^{\mathrm{WT}}$ cells that would be expected after $48 \mathrm{~h}$ competition, left them to adhere for $4 \mathrm{~h}$, and added doxycycline. We then started imaging the following day.

Cell fate analysis. For the analysis of experiments and simulations, fate information for each cell is dynamically recorded to a file and analysed using a custom software written in Matlab [15].

Entropy of cell mixing. The entropy of mixing was calculated as the Shannon entropy of a twostate system, where the states considered are the cell types (winner/loser). The entropy was then calculated as $s=-P_{1} \ln P_{1}-P_{2} \ln P_{2}$ for each cell at each frame, where $P_{1}=\frac{\# \text { winner neighbors }}{\text { total } \# \text { neighbors }}$ and $P_{2}=\frac{\# \text { loser neighbors }}{\text { total \# neighbors }}$. The entropy of the whole system was then calculated as: $S=<s>$ / $\sum$ cells.

Data and model availability. Our model has been deposited in Github (https://github.com/DGradeci/cell_compeition_paper_models). The data used for model calibration will be deposited in doi: 10.5522/04/12287465. 


\section{References}

1. Vincent, J.P., Fletcher, A.G., and Baena-Lopez, L.A. (2013). Mechanisms and mechanics of cell competition in epithelia. Nat Rev Mol Cell Biol 14, 581-591.

2. Levayer, R., and Moreno, E. (2013). Mechanisms of cell competition: themes and variations. J Cell Biol 200, 689-698.

3. Morata, G., and Ripoll, P. (1975). Minutes: mutants of Drosophila autonomously affecting cell division rate. Developmental biology 42, 211-221.

4. Amoyel, M., and Bach, E.A. (2014). Cell competition: how to eliminate your neighbours. Development 141, 988-1000.

5. Chen, C.-L., Schroeder, M.C., Kango-Singh, M., Tao, C., and Halder, G. (2012). Tumor suppression by cell competition through regulation of the Hippo pathway. Proceedings of the National Academy of Sciences 109, 484-489.

6. Madan, E., Pelham, C.J., Nagane, M., Parker, T.M., Canas-Marques, R., Fazio, K., Shaik, K., Yuan, Y., Henriques, V., and Galzerano, A. (2019). Flower isoforms promote competitive growth in cancer. Nature 572, 260-264.

7. Moreno, E., Basler, K., and Morata, G. (2002). Cells compete for decapentaplegic survival factor to prevent apoptosis in Drosophila wing development. Nature 416, 755-759.

8. Wagstaff, L., Goschorska, M., Kozyrska, K., Duclos, G., Kucinski, I., Chessel, A., HamptonO'Neil, L., Bradshaw, C.R., Allen, G.E., Rawlins, E.L., et al. (2016). Mechanical cell competition kills cells via induction of lethal p53 levels. Nat Commun 7, 11373.

9. Shraiman, B.I. (2005). Mechanical feedback as a possible regulator of tissue growth. Proceedings of the National Academy of Sciences 102, 3318-3323.

10. Levayer, R., Dupont, C., and Moreno, E. (2016). Tissue Crowding Induces Caspase-Dependent Competition for Space. Curr Biol 26, 670-677.

11. Yamamoto, M., Ohsawa, S., Kunimasa, K., and Igaki, T. (2017). The ligand Sas and its receptor PTP10D drive tumour-suppressive cell competition. Nature 542, 246.

12. Levayer, R., Hauert, B., and Moreno, E. (2015). Cell mixing induced by myc is required for competitive tissue invasion and destruction. Nature 524, 476-480.

13. Díaz-Díaz, C., de Manuel, L.F., Jimenez-Carretero, D., Montoya, M.C., Clavería, C., and Torres, M. (2017). Pluripotency surveillance by Myc-driven competitive elimination of differentiating cells. Developmental cell 42, 585-599. e584.

14. Gradeci, D., Bove, A., Charras, G., Lowe, A.R., and Banerjee, S. (2019). Single-cell approaches to cell competition: high-throughput imaging, machine learning and simulations. In Seminars in cancer biology. (Elsevier).

15. Bove, A., Gradeci, D., Fujita, Y., Banerjee, S., Charras, G., and Lowe, A.R. (2017). Local cellular neighborhood controls proliferation in cell competition. Mol Biol Cell 28, 3215-3228.

16. Nishikawa, S., Takamatsu, A., Ohsawa, S., and Igaki, T. (2016). Mathematical model for cell competition: Predator-prey interactions at the interface between two groups of cells in monolayer tissue. J Theor Biol 404, 40-50.

17. Tsuboi, A., Ohsawa, S., Umetsu, D., Sando, Y., Kuranaga, E., Igaki, T., and Fujimoto, K. (2018). Competition for Space Is Controlled by Apoptosis-Induced Change of Local Epithelial Topology. Curr Biol 28, 2115-2128 e2115.

18. Lee, S.W., and Morishita, Y. (2017). Possible roles of mechanical cell elimination intrinsic to growing tissues from the perspective of tissue growth efficiency and homeostasis. PLoS Comput Biol 13, e1005651.

19. Norman, M., Wisniewska, K.A., Lawrenson, K., Garcia-Miranda, P., Tada, M., Kajita, M., Mano, H., Ishikawa, S., Ikegawa, M., Shimada, T., et al. (2012). Loss of Scribble causes cell competition in mammalian cells. J Cell Sci 125, 59-66.

20. Rejniak, K.A., and Anderson, A.R. (2011). Hybrid models of tumor growth. Wiley Interdiscip Rev Syst Biol Med 3, 115-125.

21. Zhang, L., Wang, Z., Sagotsky, J.A., and Deisboeck, T.S. (2009). Multiscale agent-based cancer modeling. J Math Biol 58, 545-559. 
22. Graner, F., and Glazier, J.A. (1992). Simulation of biological cell sorting using a twodimensional extended Potts model. Phys Rev Lett 69, 2013-2016.

23. Fletcher, A.G., Osterfield, M., Baker, R.E., and Shvartsman, S.Y. (2014). Vertex Models of Epithelial Morphogenesis. Biophys J 106, 2291-2304.

24. Cadart, C., Monnier, S., Grilli, J., Sáez, P.J., Srivastava, N., Attia, R., Terriac, E., Baum, B., Cosentino-Lagomarsino, M., and Piel, M. (2018). Size control in mammalian cells involves modulation of both growth rate and cell cycle duration. Nature communications 9, 3275 .

25. Abercrombie, M. (1979). Contact inhibition and malignancy. Nature 281, 259.

26. Lieberman, M., and Glaser, L. (1981). Density-dependent regulation of cell growth: an example of a cell-cell recognition phenomenon. The Journal of membrane biology 63, 1-11.

27. Azar, R., Susini, C., Bousquet, C., and Pyronnet, S. (2010). Control of contact-inhibition by 4EBP1 upregulation. Cell Cycle 9, 1241-1245.

28. Eisenhoffer, G.T., Loftus, P.D., Yoshigi, M., Otsuna, H., Chien, C.B., Morcos, P.A., and Rosenblatt, J. (2012). Crowding induces live cell extrusion to maintain homeostatic cell numbers in epithelia. Nature 484, 546-549.

29. Kocgozlu, L., Saw, Thuan B., Le, Anh P., Yow, I., Shagirov, M., Wong, E., Mège, R.-M., Lim, Chwee T., Toyama, Y., and Ladoux, B. (2016). Epithelial Cell Packing Induces Distinct Modes of Cell Extrusions. Current Biology 26, 2942-2950.

30. Gibson, M.C., Patel, A.B., Nagpal, R., and Perrimon, N. (2006). The emergence of geometric order in proliferating metazoan epithelia. Nature 442, 1038-1041.

31. Farhadifar, R., Roper, J.C., Aigouy, B., Eaton, S., and Julicher, F. (2007). The influence of cell mechanics, cell-cell interactions, and proliferation on epithelial packing. Curr Biol 17, 20952104.

32. Marinari, E., Mehonic, A., Curran, S., Gale, J., Duke, T., and Baum, B. (2012). Live-cell delamination counterbalances epithelial growth to limit tissue overcrowding. Nature 484, $542-$ 545.

33. Gudipaty, S.A., Lindblom, J., Loftus, P.D., Redd, M.J., Edes, K., Davey, C., Krishnegowda, V., and Rosenblatt, J. (2017). Mechanical stretch triggers rapid epithelial cell division through Piezo1. Nature 543, 118.

34. Kucinski, I., Dinan, M., Kolahgar, G., and Piddini, E. (2017). Chronic activation of JNK JAK/STAT and oxidative stress signalling causes the loser cell status. Nature communications $8,136$.

35. Basan, M., Risler, T., Joanny, J.F., Sastre-Garau, X., and Prost, J. (2009). Homeostatic competition drives tumor growth and metastasis nucleation. HFSP journal 3, 265-272.

36. Harris, A.R., and Charras, G. (2011). Experimental validation of atomic force microscopy-based cell elasticity measurements. Nanotechnology 22, 345102.

37. Harris, A.R., Peter, L., Bellis, J., Baum, B., Kabla, A.J., and Charras, G.T. (2012). Characterizing the mechanics of cultured cell monolayers. Proceedings of the National Academy of Sciences 109, 16449-16454.

38. Latorre, E., Kale, S., Casares, L., Gómez-González, M., Uroz, M., Valon, L., Nair, R.V., Garreta, E., Montserrat, N., and del Campo, A. (2018). Active superelasticity in three-dimensional epithelia of controlled shape. Nature 563, 203.

39. Swat, M.H., Thomas, G.L., Belmonte, J.M., Shirinifard, A., Hmeljak, D., and Glazier, J.A. (2012). Multi-scale modeling of tissues using CompuCell3D. Methods Cell Biol 110, 325-366.

40. Li, J.F., and Lowengrub, J. (2014). The effects of cell compressibility, motility and contact inhibition on the growth of tumor cell clusters using the Cellular Potts Model. J Theor Biol 343, 79-91.

41. Hogan, C., Dupre-Crochet, S., Norman, M., Kajita, M., Zimmermann, C., Pelling, A.E., Piddini, E., Baena-Lopez, L.A., Vincent, J.P., Itoh, Y., et al. (2009). Characterization of the interface between normal and transformed epithelial cells. Nat Cell Biol 11, 460-467.

42. Kajita, M., Hogan, C., Harris, A.R., Dupre-Crochet, S., Itasaki, N., Kawakami, K., Charras, G., Tada, M., and Fujita, Y. (2010). Interaction with surrounding normal epithelial cells influences signalling pathways and behaviour of Src-transformed cells. J Cell Sci 123, 171-180. 


\section{Acknowledgements}

Funding. This work was supported by Engineering and Physical Sciences Research Council (EPSRC) $\mathrm{PhD}$ studentships to DG and AB. SB acknowledges support from the Royal Society (URF/R1/180187). GV is supported by BBSRC grant BB/S009329/1 to AL and GC.

Author Contributions. GC, SB, and AL conceived and designed the research. DG developed and performed computational simulations. $\mathrm{AB}$ and $\mathrm{GV}$ performed experiments. $\mathrm{DG}$ analysed data with some help from GV. DG, GC, AL and SB wrote the paper.

Competing Interests. The authors declare that they have no competing financial interests.

Data and materials availability. Additional data and materials are available online. 


\section{Figures}

\section{A}

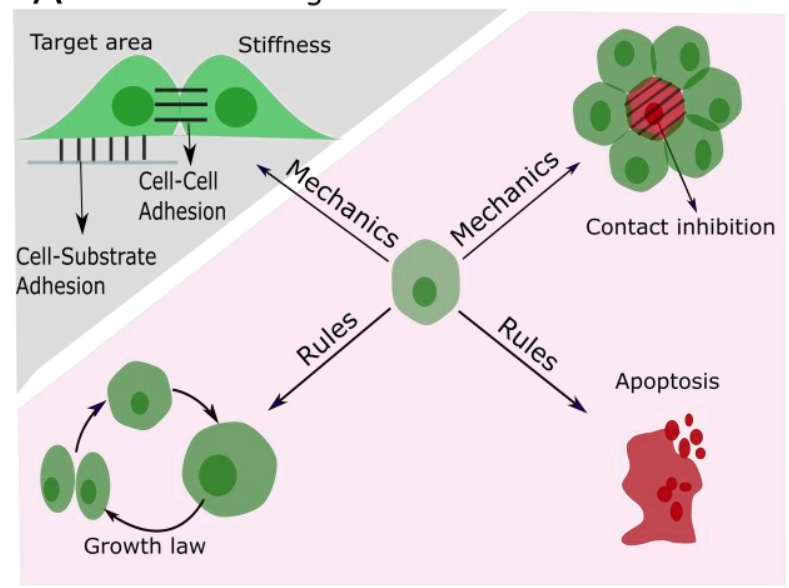

D Live cell extrusions

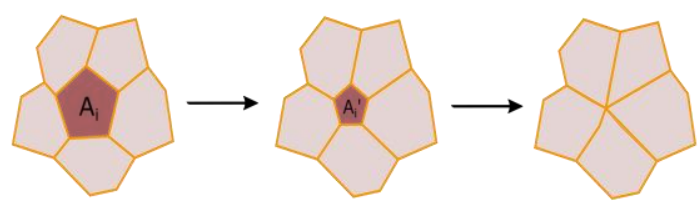

Extrusion occurs if $A_{i} \leq \frac{<A>}{2}$
B

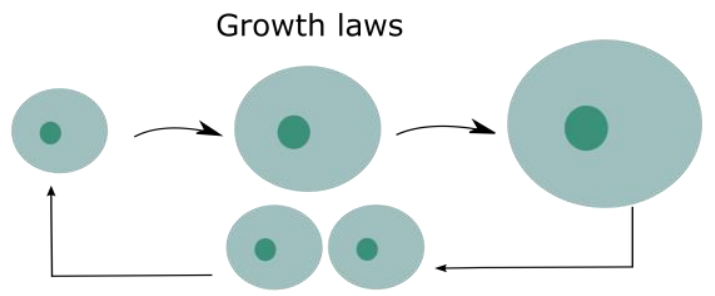

C

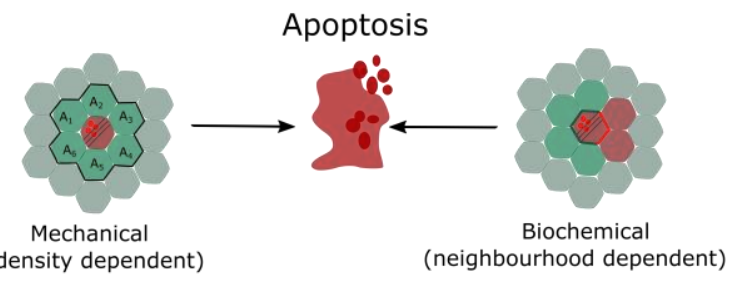

$\mathrm{E}$

Contact Inhibition

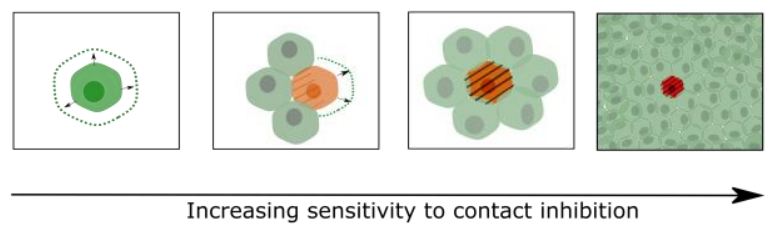

$\frac{d A_{T}}{d t}=G \exp \left(-k\left(A-A_{T}\right)^{2}\right)$

FIG. 1: Physical and decision-making components of the multi-layered computational model. (A) Schematic of the single cell behaviours incorporated into the multi-scale agent-based model. A cellular Potts model is used to model cellular mechanical properties, such as adhesion and compressibility (greyed region). An agent-based model (pink region) comprises cellular automata rules describing cell growth, division, apoptosis and contact inhibition. These rules are algorithmically executed for each cell at each time point. (B) Cells grow linearly in time and follow an adder mechanism for division control, in which a threshold size $\Delta A_{\text {tot }}$ must be added before a cell can divide (Fig S1). (C) Two separate rules were implemented for apoptosis during mechanical competition (Fig S2A) and biochemical competition (Fig S3A). (D) Cells can also be removed from epithelia through live cell extrusion. Extrusion occurs if cell $i$ 's area, $A_{i}$, decreases below half of the mean cell area of the population, $\langle A\rangle / 2$. (E) Schematic depiction of contact inhibition showing cell growth and movement are arrested when local cell density increases. The growth rate of a cell depends on how far its actual area $A$ is from its target area $A_{T}$. 


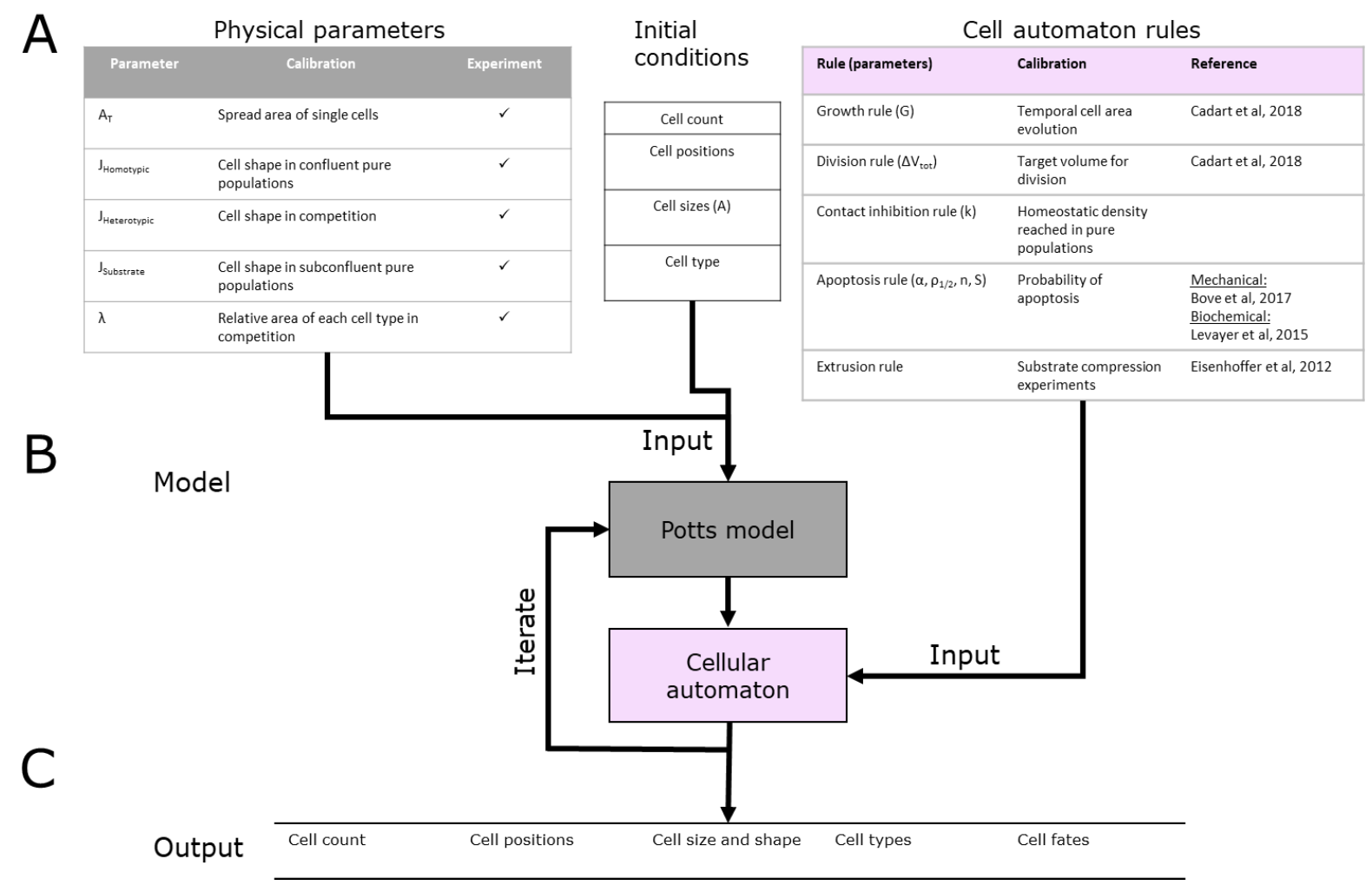

Figure 2: Simulation workflow. (A) Input variables are separated into three categories: Physical parameters, Cell automaton rules, and Initial conditions. Physical parameters (grey) describe the cellular mechanical properties and these are calibrated using the experimental measurements given in the table. Cell automaton rules (pink) are run for each cell at each time point. They are parametrized using heuristic variables calibrated based on experimental data acquired on MDCK cells. Initial conditions describe the parameters needed to initialize the simulations. These replicate experimental conditions and are randomized with a chosen set of rules for each new simulation. (B) Multiscale agent-based model consisting of a Cellular Potts model coupled to a cellular automaton. The Potts model computes the mechanical equilibrium state of the cell at each timestep based on the mechanical state of the cell and the values of cell parameters updated by the cellular automaton at the previous timestep. As input, it requires the initial conditions and the physical parameters of each cell. The cellular automaton model updates cellular parameters at each time point. As input at each timestep, it requires the conditions at the previous timestep computed by the Potts model and a table of parameters. (C) The model outputs cell count, cell positions, cell size and shape, cell type, and cell fates for all time points. These outputs can be compared to experimental data. 

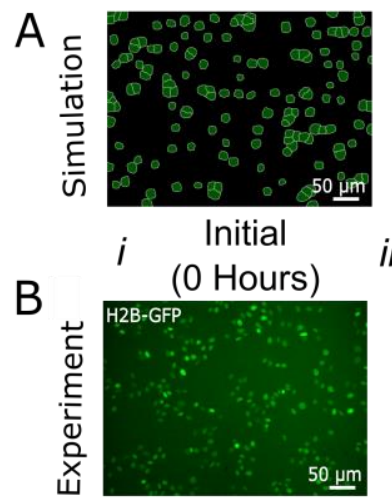

C
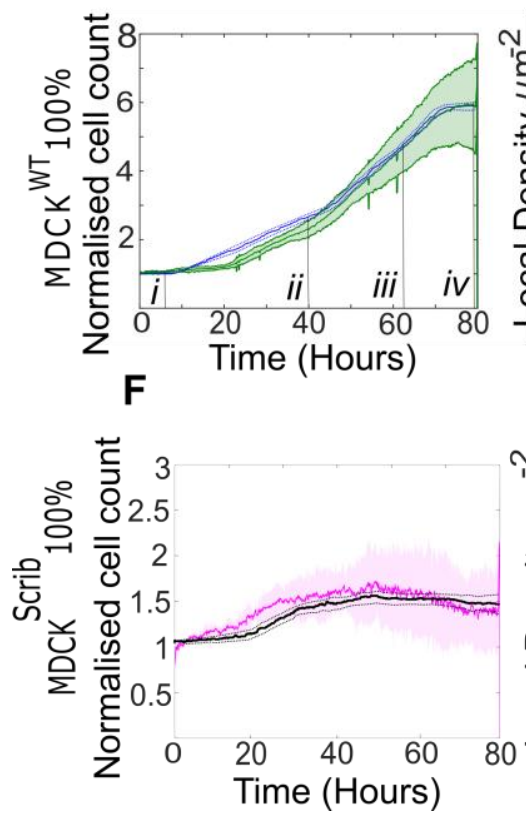

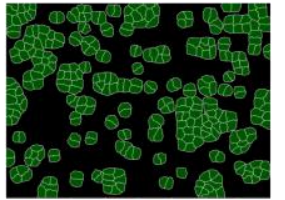

Pre-confluence (30 Hours)
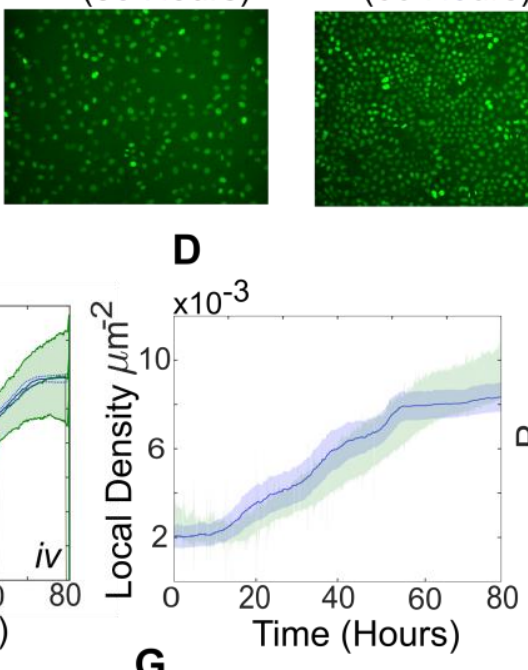

G

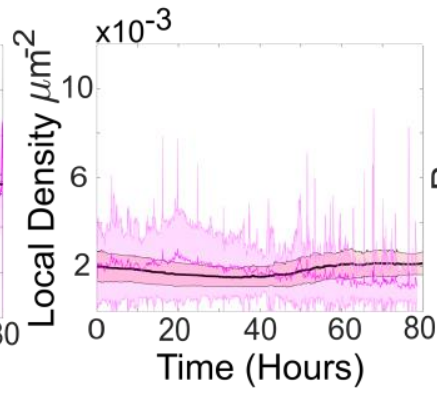

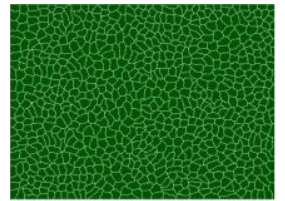

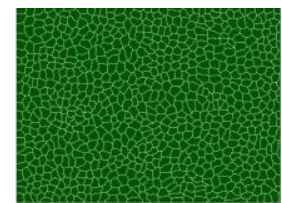

Confluence (60 Hours)

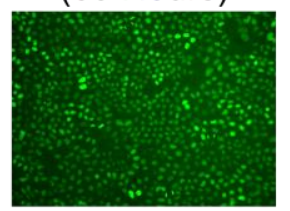

iv Post-confluence (80 Hours)

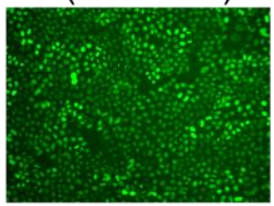

E
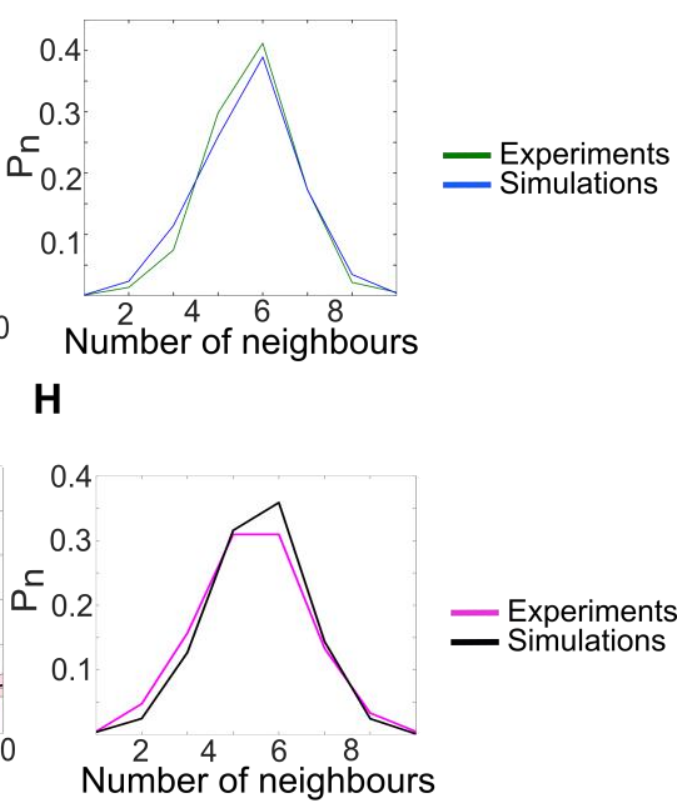

Fig 3: Model simulations capture the dynamics of growth and homeostasis in pure cell populations. (A) Simulation snapshots of the growth of a pure population of winner cells (movie S1). Cells are initially separated by free space (black). Each image corresponds to one computational field of view, representing $530 \mu \mathrm{m} \times 400 \mu \mathrm{m}$. (B) Experimental snapshots of $\mathrm{MDCK}^{\mathrm{WT}}$ (winner) cells expressing the nuclear marker H2B-GFP (movie S2). Each image corresponds to $530 \mu \mathrm{m} \times 400 \mu \mathrm{m}$ and is acquired by wide-field epifluorescence using $20 \mathrm{x}$ magnification. The timing of each image is indicated between the two image rows. (C) Normalised cell count as a function of time for winner cells in simulations (blue) and $\mathrm{MDCK}^{\mathrm{WT}}$ experiments (green). (i-iv) indicate the time points at which the snapshots in (A-B) were taken. (D) Average local cellular density as a function of time for the same data as C. (E) Distribution of sidedness of cells post confluence. The curves indicate the proportion of cells as a function of number of neighbours. (C-E) green curves represent experimental data and blue curves simulated data. (F-H) are same as (C-E) for pure populations of loser cells (MDCK ${ }^{\text {Scrib}}$ ). Magenta curves are experimental data (movie S3) and black curves represent simulated data. (C-H) Data are pooled from three biological replicates imaging four fields of view each, and from 12 simulations. The solid line indicates the mean and the shaded area indicates the standard deviation. Parameters used for the simulations in this figure are listed in Table S1. 
A
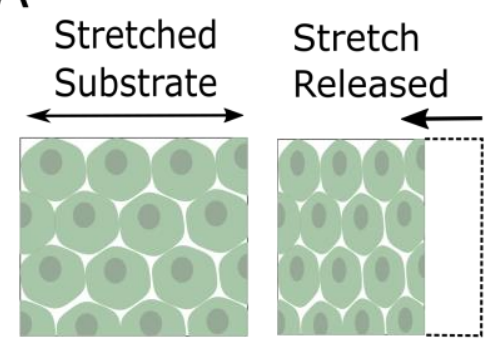

Apoptosis

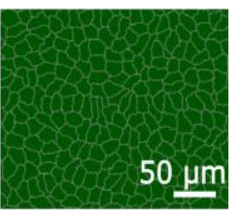

Pre-release

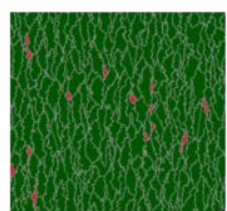

$\mathrm{t}=-1$ hour

Release \& Extrusions
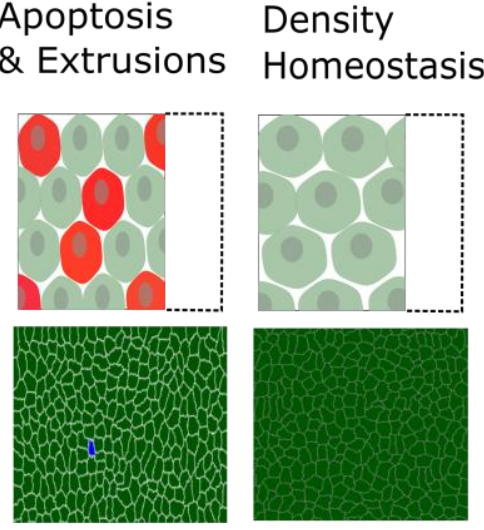

post-release

post-release

$t=0$ mins $t=1$ hour

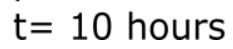

B

Figure 4: Return to homeostasis in response to a sudden increase in local density. (A) Simulation snapshots of winner cells grown to confluence on a stretched silicon substrate, and subjected to a sudden increase in density after stretch release. Top row: cartoon diagrams depicting the experiment. Bottom row: snapshots of simulations. Homeostatic density is restored after stretch release thanks to cell elimination by either extrusion (red) or apoptosis (blue). (B) Evolution of cell density as a function of time in response to a step increase in cell density at $\mathrm{t}=0$ minutes. Density in simulations is indicated by the black line and experimental data are shown by green diamond markers [28]. The shaded region around the black line indicates the standard deviation of $n=5$ experiments. The whiskers around the diamond markers indicate the standard deviation of the experimental measurements. 

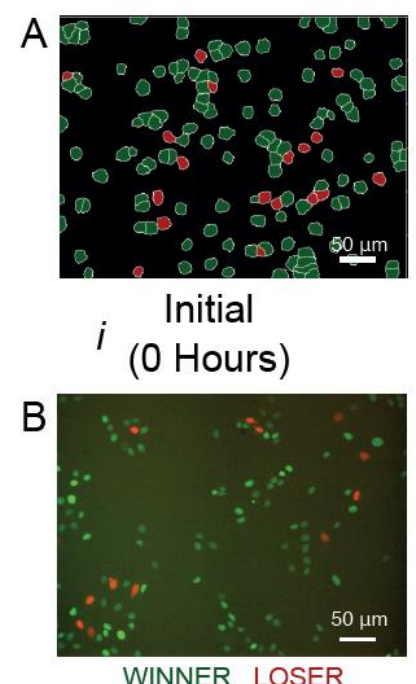

iii
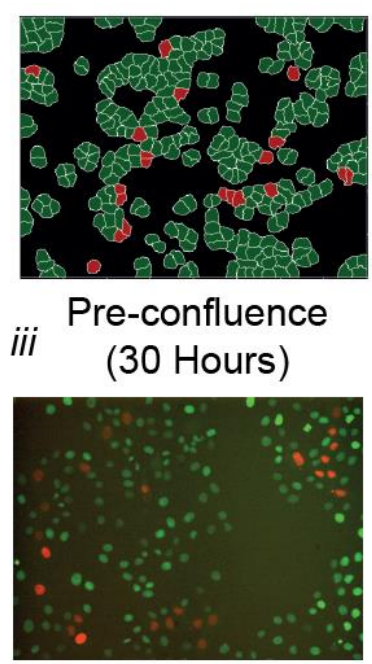

ROSER

C

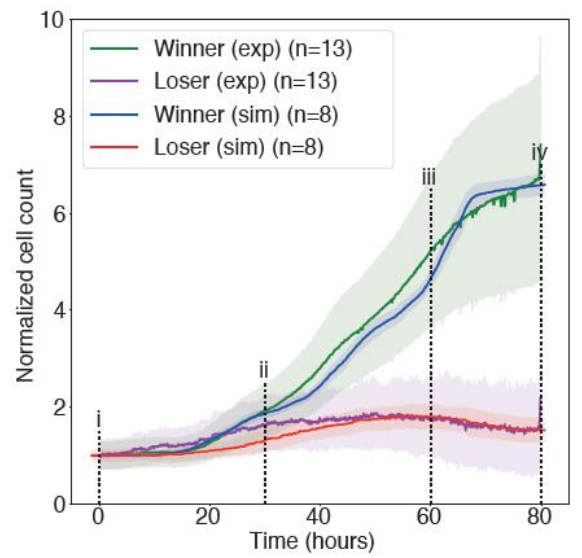

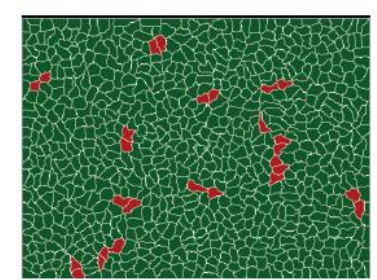

iii Confluence

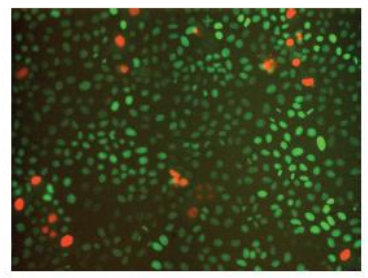

D

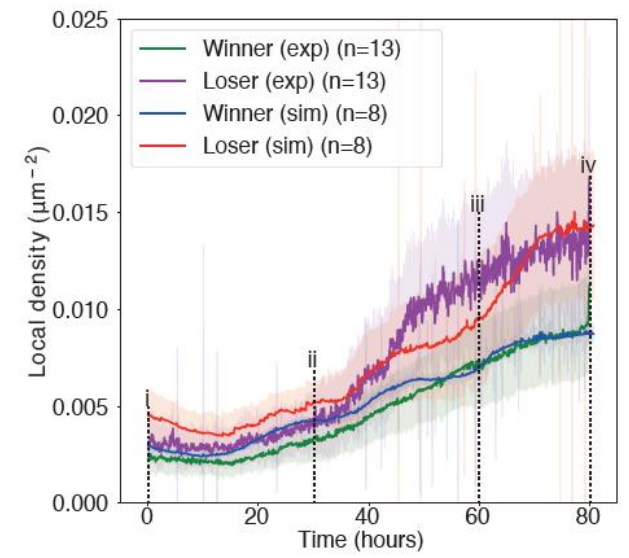

Figure 5: Cell competition in co-cultures of cells with different homeostatic densities. (A) Simulation snapshots of competition between $90 \%$ winner (green) and $10 \%$ loser cells (red) (movie S4). Cells are initially separated by free space (black). Each image corresponds to $530 \mu \mathrm{m} \times 400 \mu \mathrm{m}$. (B) Experimental snapshots of competition between $90 \%$ $\mathrm{MDCK}^{\mathrm{WT}}$ cells (winner, green) and $10 \% \mathrm{MDCK}^{\mathrm{Scrib}}$ cells (loser, red) (movie S5). MDCK ${ }^{\mathrm{WT}}$ express the nuclear marker H2B-GFP, while MDCK ${ }^{\text {Scri }}$ express the nuclear marker H2B-RFP. Each image corresponds to $530 \mu \mathrm{m} \times 400 \mu \mathrm{m}$ and is acquired by wide-field epifluorescence using 20x magnification. The timing of snapshots is indicated in between rows A and B. (C) Evolution of normalised cell count for winner cells (simulations: blue line, experiments: green line) and losercells (simulations: red line, experiments: purple line) in experiments initiated with a 90:10 ratio of winner:loser cells. Data are pooled from three biological replicates imaging four fields of view for the experiments and from 12 simulations. (i-iv) indicate the time points at which the snapshots in (A-B) were taken. (D) Temporal evolution of the local cell density for the simulations and experiments shown in (C). The local density is defined in Fig S2B. (C-D) Solid lines indicate the average of the data and the shaded area indicates the standard deviation. Parameters used for the simulations in this figure are in Table S1. 


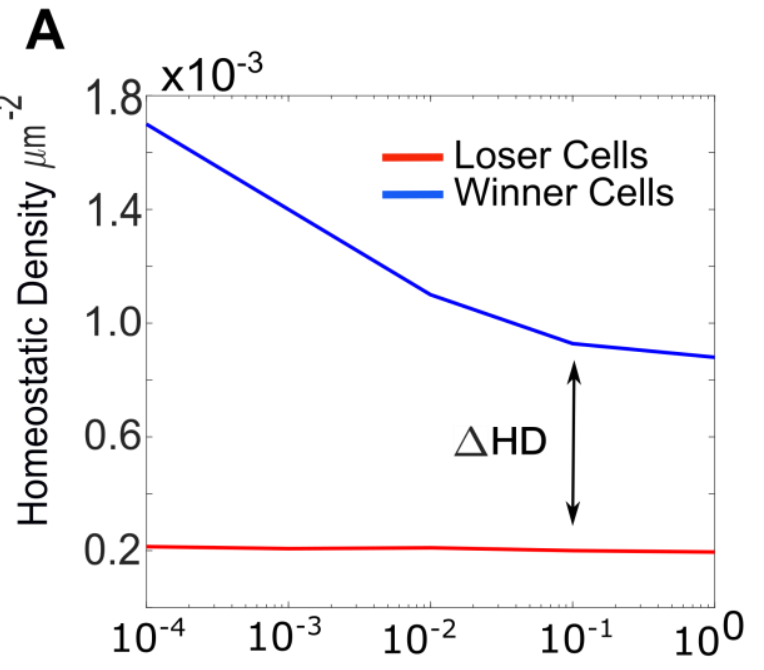

C

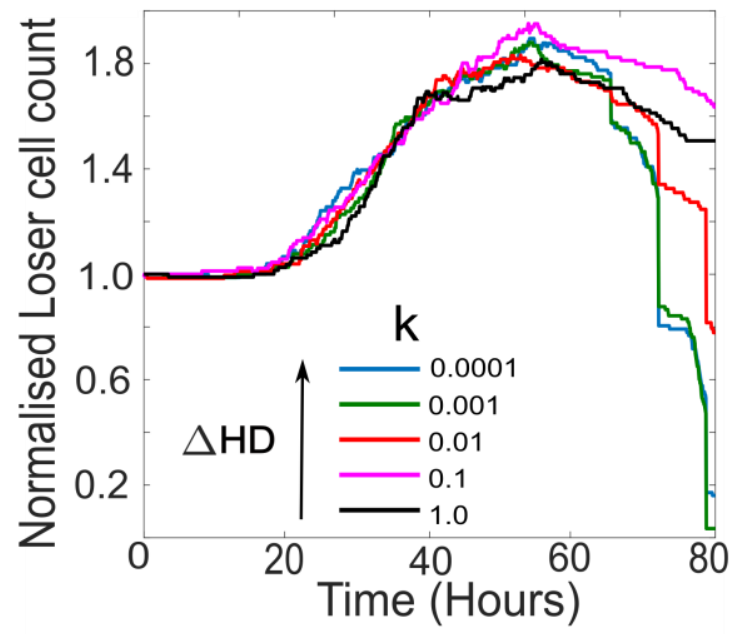

$\mathbf{E}$

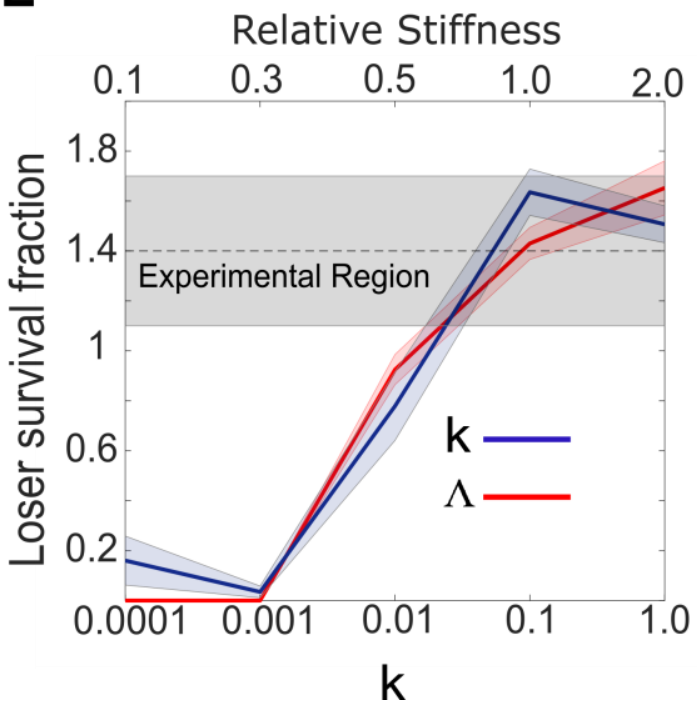

B
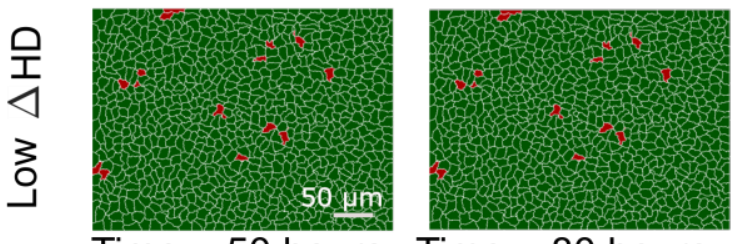

Time $=50$ hours

(Confluency)

Time $=80$ hours

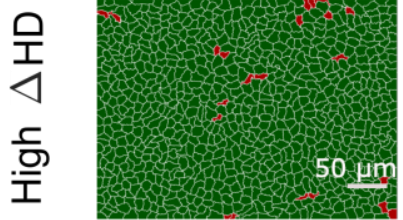

D

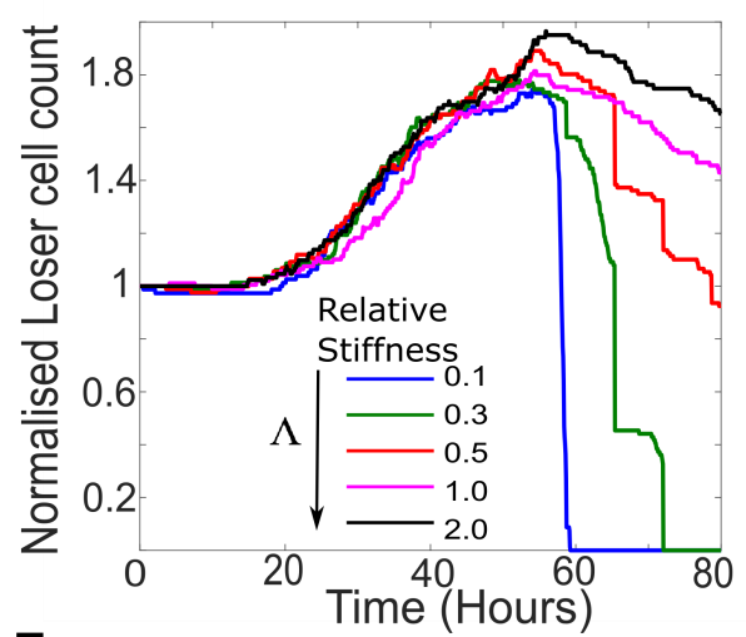

$\mathbf{F}$

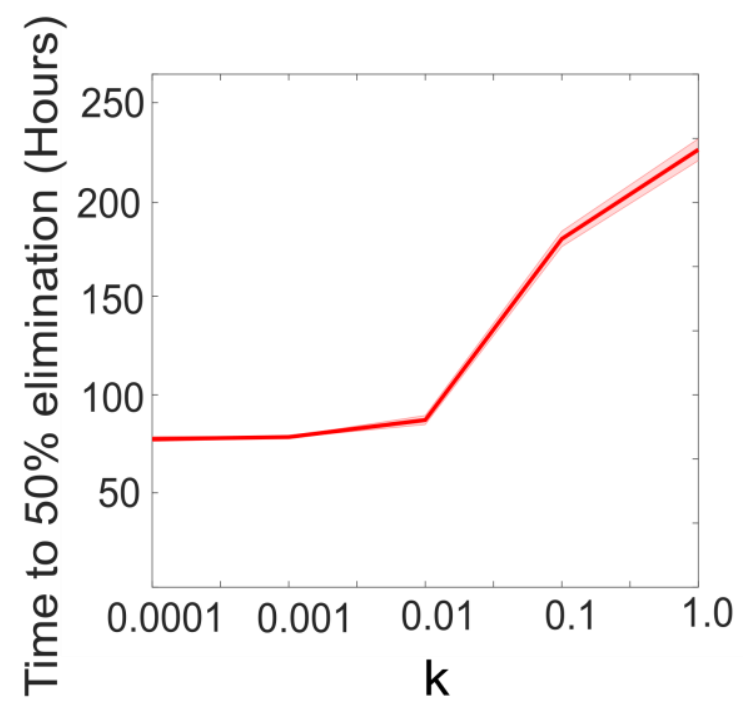

Figure 6: Cellular stiffness and homeostatic density control the outcome of mechanical competition. (A) Evolution of homeostatic density as a function of the parameter $k$, quantifying the sensitivity to contact inhibition. Data are shown for pure populations of winner (blue) and loser (red) cells. (B) Simulation snapshots of competition between $90 \%$ winner cells (green) and $10 \%$ loser cells (red). The top two panels show the population evolution for a small difference in homeostatic density $\triangle H D$ between the two cell types. The bottom two panels show the population 
evolution for a large $\triangle H D$ between the two cell types. Each image corresponds to $530 \mu \mathrm{m} \times 400 \mu \mathrm{m}$. (C) Normalised cell count for loser cells in competition simulations for different values of the contact inhibition parameter $k$. As $k$ decreases, $\triangle H D$ increases. (D) Normalised cell count for loser cells in competition simulations for different values of the relative stiffness parameter $\Lambda=\lambda_{\text {loser }} / \lambda_{\text {winner }}$. Winner cells have a fixed stiffness of 1.0 . Snapshots of competition are shown in Fig. S6A-B for $\Lambda=0.3$ and $\Lambda=2$. (E) Loser cell survival fraction after 80 hours in simulations run with different parameters for relative stiffness $\Lambda$ (red line) and contact inhibition $k$ (blue line). Shaded blue and red regions denote the standard deviation. The gray shaded region indicates the survival fraction of loser cells observed in experiments after $80 \mathrm{~h}$. The $\mathrm{x}$-axis scale is indicated on the top of the graph for $\Lambda$ and on the bottom of the graph for $k$. (F) Time to $50 \%$ elimination of loser cells as a function of the contact inhibition parameter. The solid line indicates the mean and the shaded regions the standard deviation. Parameters used for the simulations in this figure are in Table S2. 


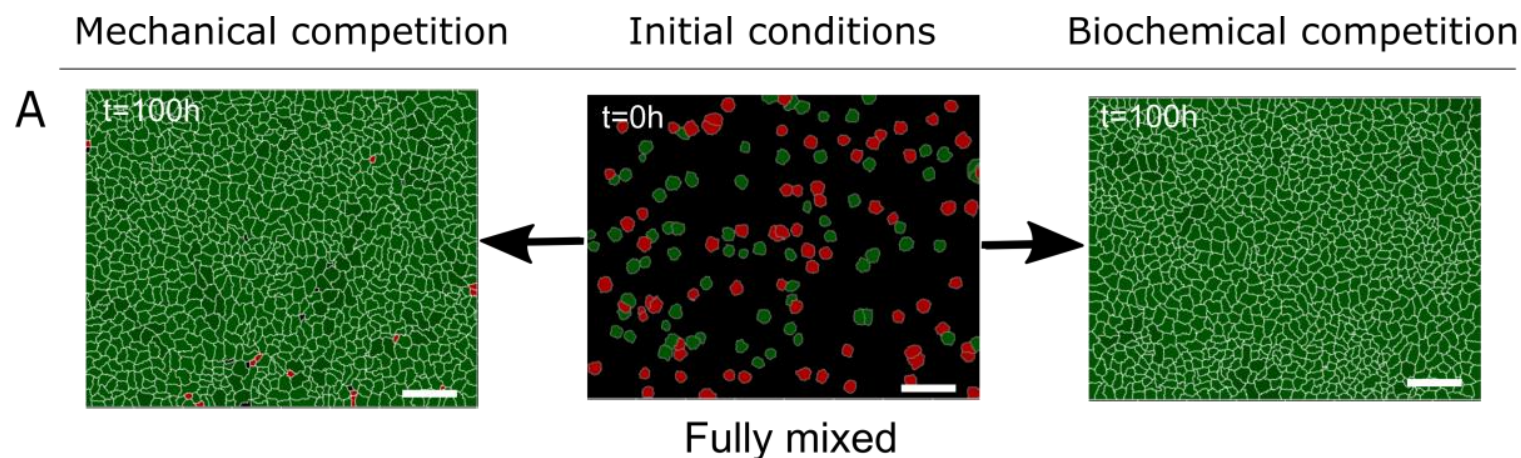

\section{B}

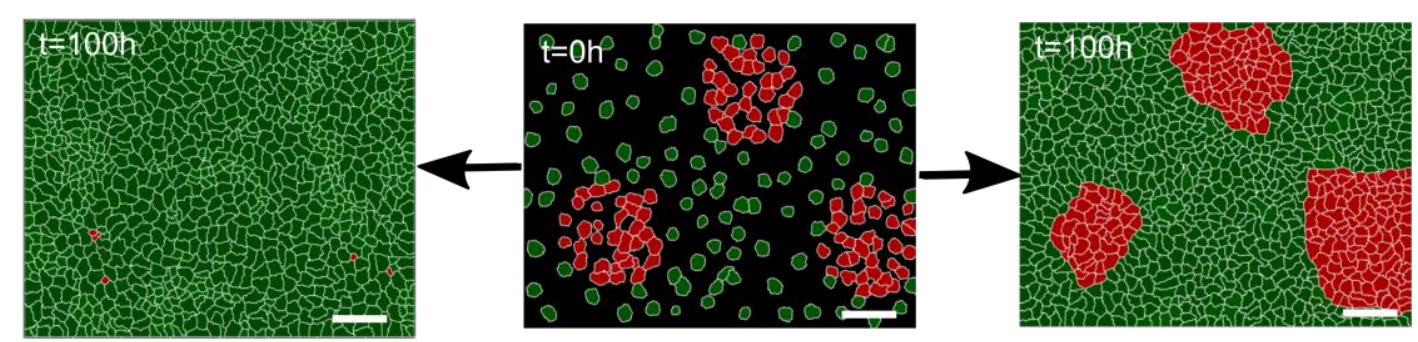

Partially sorted

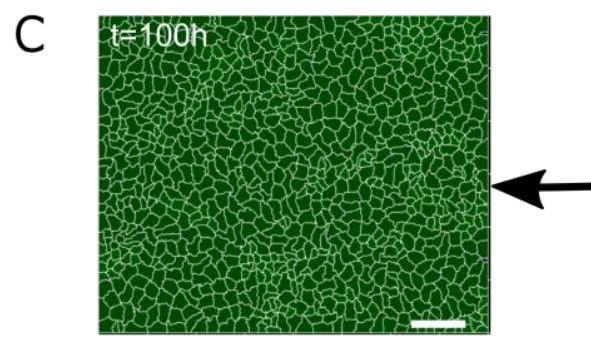

D

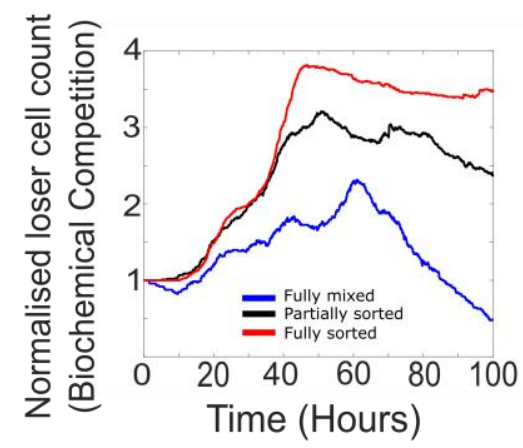

$\mathrm{E}$

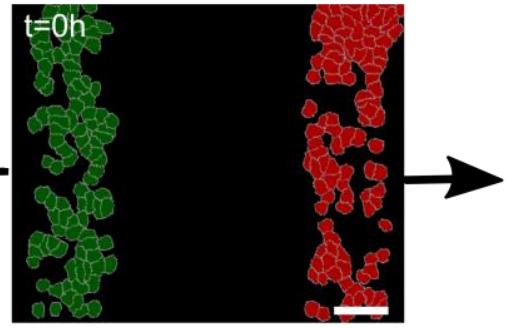

Fully sorted

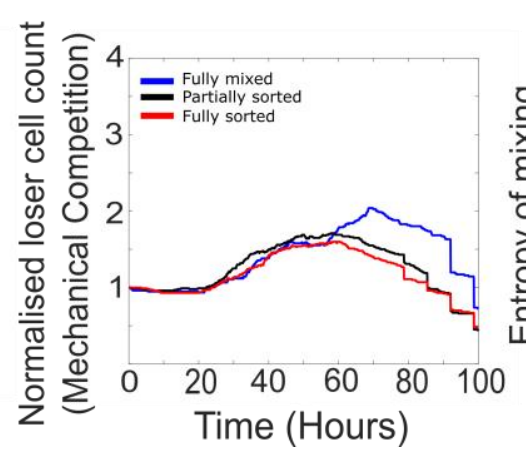

$\mathrm{F}$

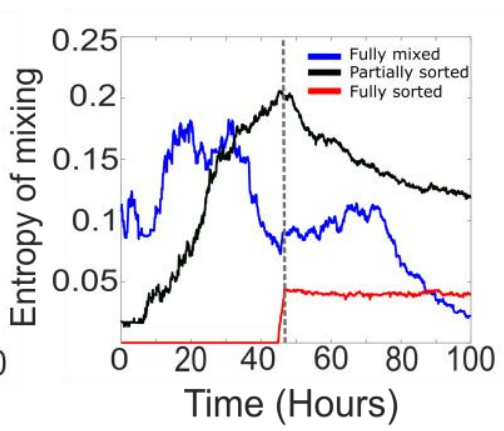

Fig 7: Tissue organisation and intercellular adhesion strength govern the outcome of biochemical competition. (A-C) The middle panels show the initial configuration of a competition between 50\% loser (green) and 50\% winner (red) cells for various seeding arrangements (fully mixed, partially sorted, fully sorted). The right panels show a representative outcome for biochemical competition. The left panels show a representative outcome for mechanical competition. Cells are initially separated by free space (black). (D) Normalised loser cell count for the three configurations for biochemical competition (A-C, right hand column). (E) Normalised loser cell count of loser cells from the three configurations for mechanical competition (A-C, left hand column). (F) Temporal evolution of the entropy of cell mixing for the three different configurations for biochemical competition. The dashed line indicates the time when the epithelium reaches confluence. Parameters used for the simulations in this figure are in Table S3. 


\section{Supplementary Materials}

\section{Supplementary Figures}
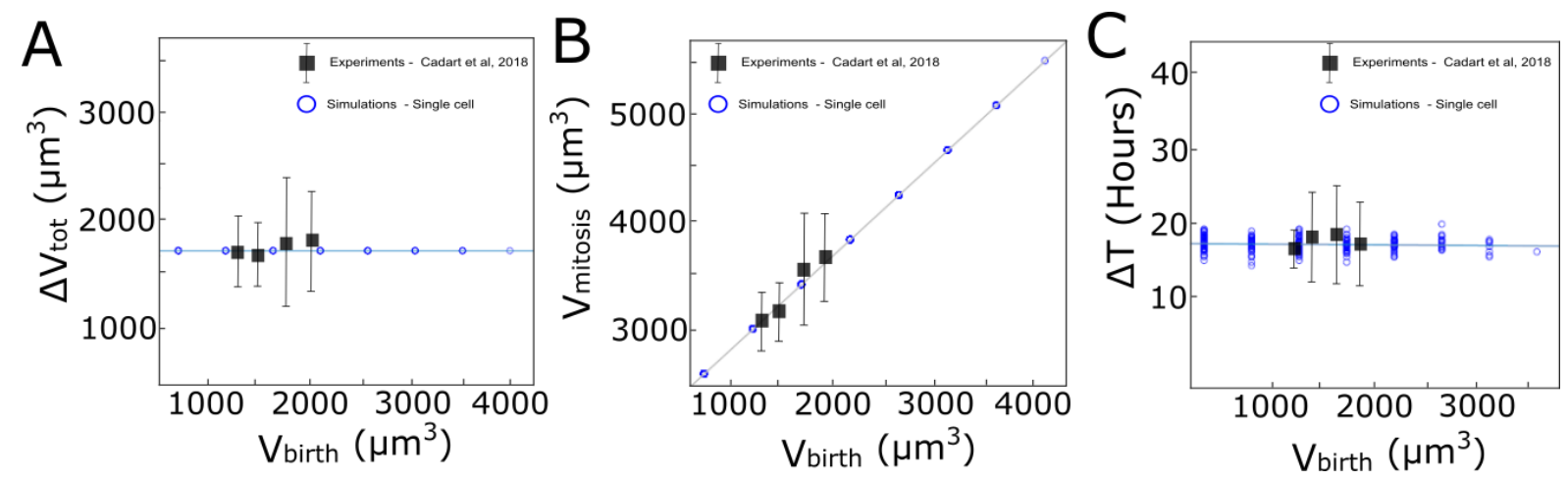

Fig S1: Computational implementation of the adder model of growth followed by MDCK ${ }^{\mathrm{WT}}$ cells. The graphs show the relationship between: (A) added volume $\Delta \mathrm{V}_{\text {tot }}$ during one cell cycle and volume at birth $\mathrm{V}_{\text {birth }},(\mathbf{B})$ the volume at mitosis $\mathrm{V}_{\text {mitosis }}$ and $\mathrm{V}_{\text {birth }},(\mathbf{C})$ the cell cycle duration $\Delta \mathrm{T}_{\text {tot }}$ and $\mathrm{V}_{\text {birth. }}$. Black squares: Experimental data from [24]. Blue circles: Computational implementation of the adder model for single cells in our simulations. A similar set of rules was implemented for area assuming a constant cell height. 


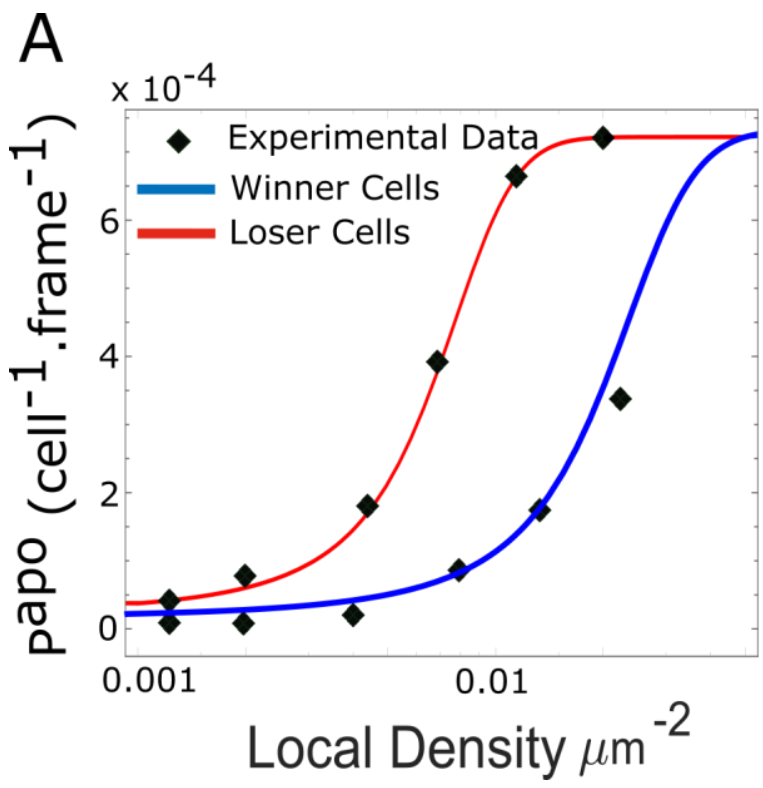

$\mathrm{B}$

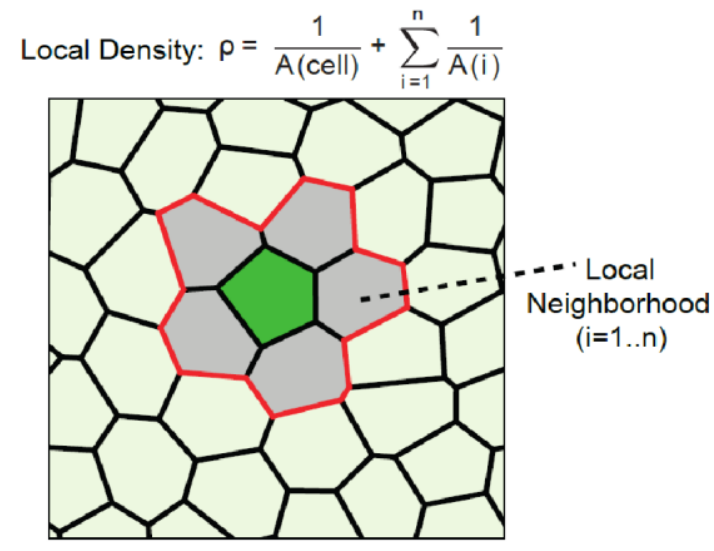

Fig S2: Density dependent apoptosis. A. Probability of apoptosis as a function of local density for mechanical competition for winners (MDCK ${ }^{\mathrm{WT}}$, blue) and losers $\left(\mathrm{MDCK}^{\text {Scrib }}\right.$, red). Markers denote experimental data for winner and loser cells. For winners and losers, the experimental data was fitted with the relationship:

$$
p_{\text {apo }}(\rho)=\frac{p_{\text {apo } \max }}{\left(1+e^{-\alpha\left(\rho-\rho_{1 / 2}\right)}\right)}
$$

with $\rho$ the local density. $p_{\text {apo max }}$ was chosen to be the same for winners as for losers. B. Definition of the local density $\rho$. The local cell density $\rho$ for the cell of interest (green) was defined as the inverse of the sum of area of the cell of interest and its first neighbours (grey). 
bioRxiv preprint doi: https://doi.org/10.1101/729731; this version posted July 13, 2020. The copyright holder for this preprint (which was not certified by peer review) is the author/funder, who has granted bioRxiv a license to display the preprint in perpetuity. It is made available under

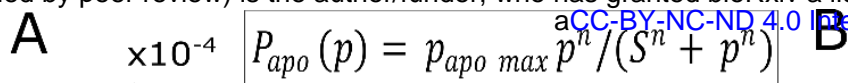

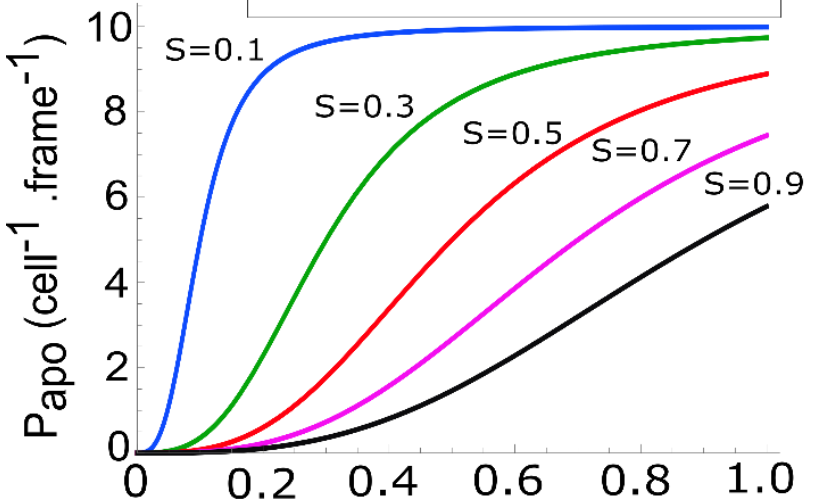

Fraction of perimeter in heterotypic contact

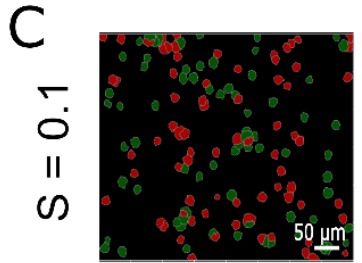

0 Hours

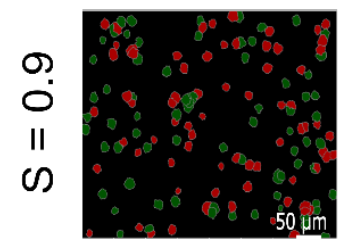

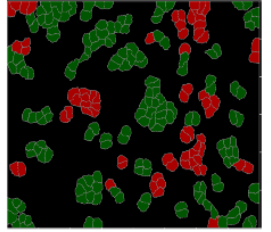

30 Hours

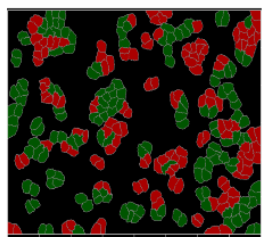

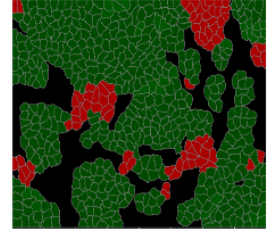

60 Hours

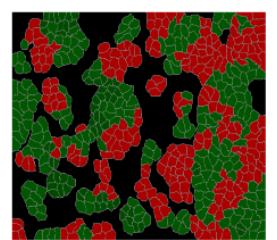

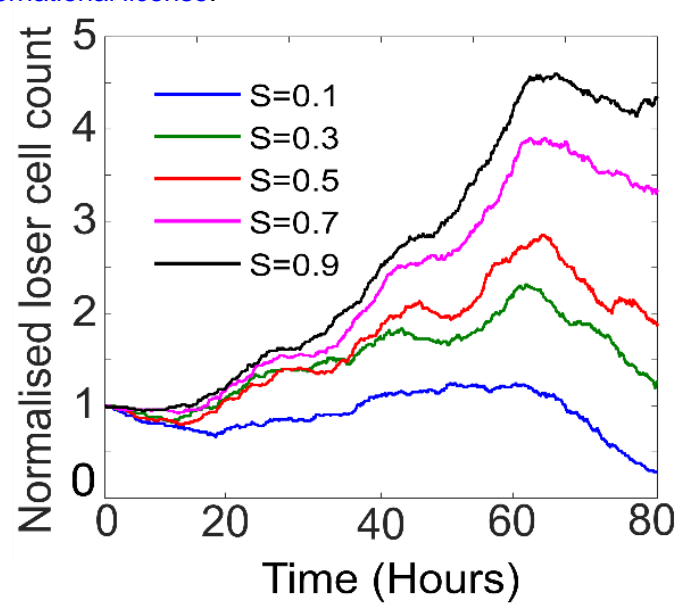

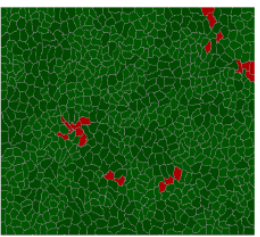

80 Hours

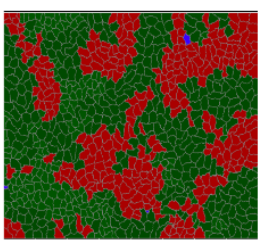

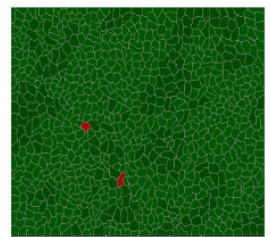

120 Hours

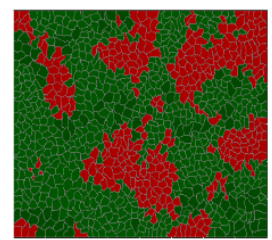

FIG S3: Contact dependent apoptosis for biochemical competition. (A) Probability of apoptosis as a function of the fraction of the perimeter engaged in heterotypic contact. The probability of apoptosis is parametrized by a Hill function, whose equation is shown above the graph. $S$ is the steepness parameter of the Hill function, $p$ the fraction of the perimeter in heterotypic contact and $n=3$ was fixed in our simulations. (B) Evolution of normalised loser cell counts as a function of $S$ with $n=3$. (C) Simulation snapshots of biochemical competition initiated with $50 \%$ winner cells (green) and 50\% loser cells (red). Top: For a low value of the steepness $S$ of the Hill function, loser cells are rapidly eliminated. Bottom: For a high value of the steepness $S$, winners and losers coexist. See movie S6. (B-C) Parameters used for the simulations in this figure are in Table S3. 
bioRxiv preprint doi: https://doi.org/10.1101/729731; this version posted July 13, 2020. The copyright holder for this preprint (which was not certified by peer review) is the author/funder, who has granted bioRxiv a license to display the preprint in perpetuity. It is made available under

A

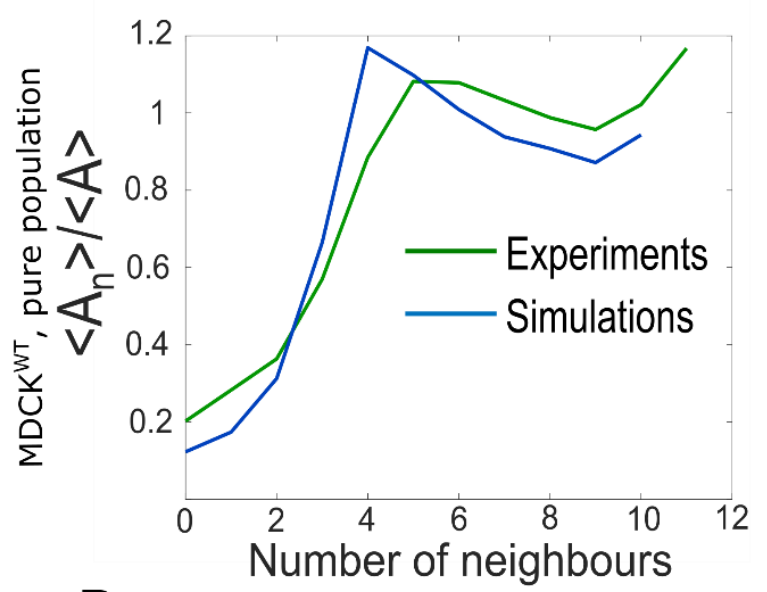

B

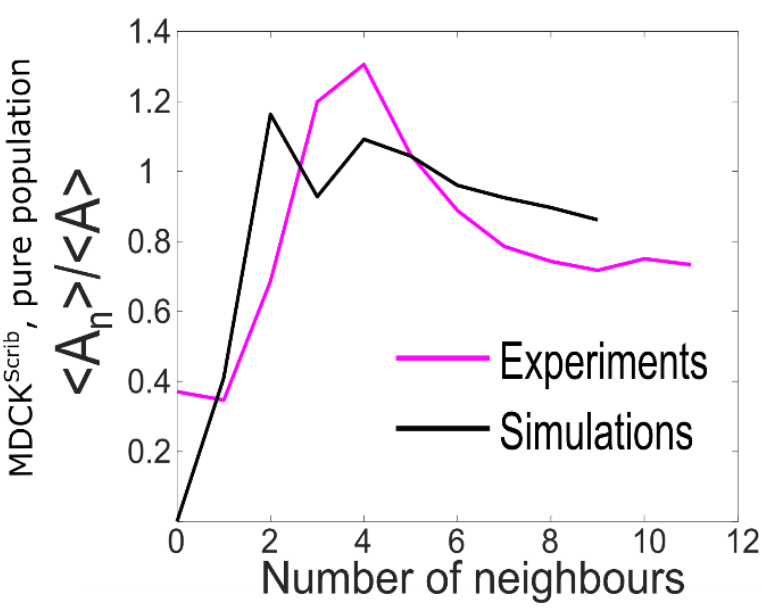

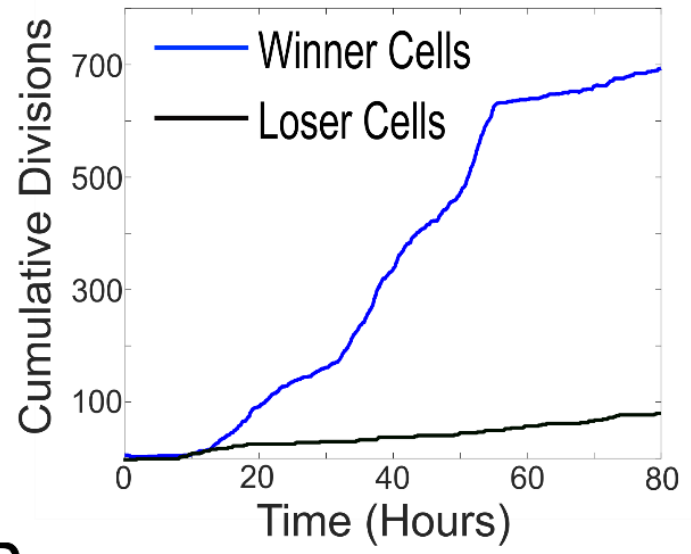

D

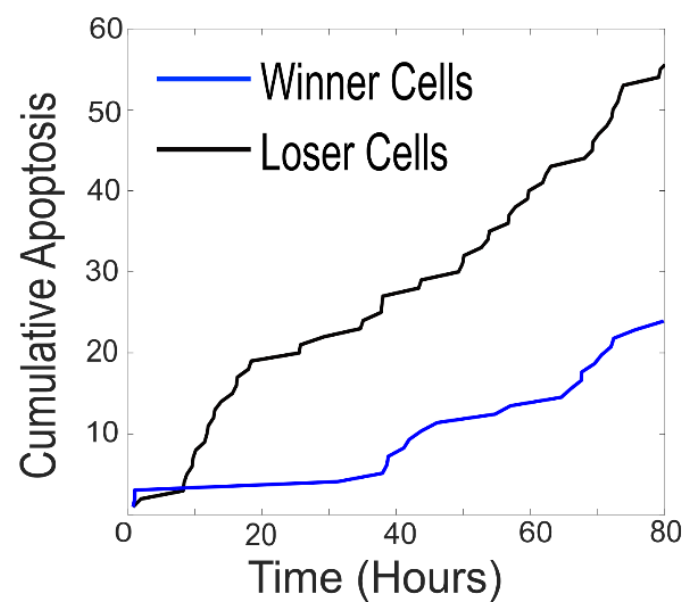

FIG S4: Comparison between simulations and experiments for pure populations and mechanical competition. (A) Ratio of average area of cells with $n$ neighbours to the average area of all cells as a function of number of neighbours for winner cells. The green line represents experiments and the blue line simulations. (B) Ratio of average area of cells with $n$ neighbours to the average area of all cells as a function of number of neighbours for loser cells. The pink line represents experiments and the black line simulations. (C) Cumulative divisions in simulations of mechanical competition for winner cells (blue) and loser cells (black) in one representative simulation. (D) Cumulative apoptoses in simulations of mechanical competition for winner cells (blue) and loser cells (black) in one representative simulation. (CD) data averaged over three simulations. 
bioRxiv preprint doi: https://doi.org/10.1101/729731; this version posted July 13, 2020. The copyright holder for this preprint (which was not certified by peer review) is the author/funder, who has granted bioRxiv a license to display the preprint in perpetuity. It is made available under
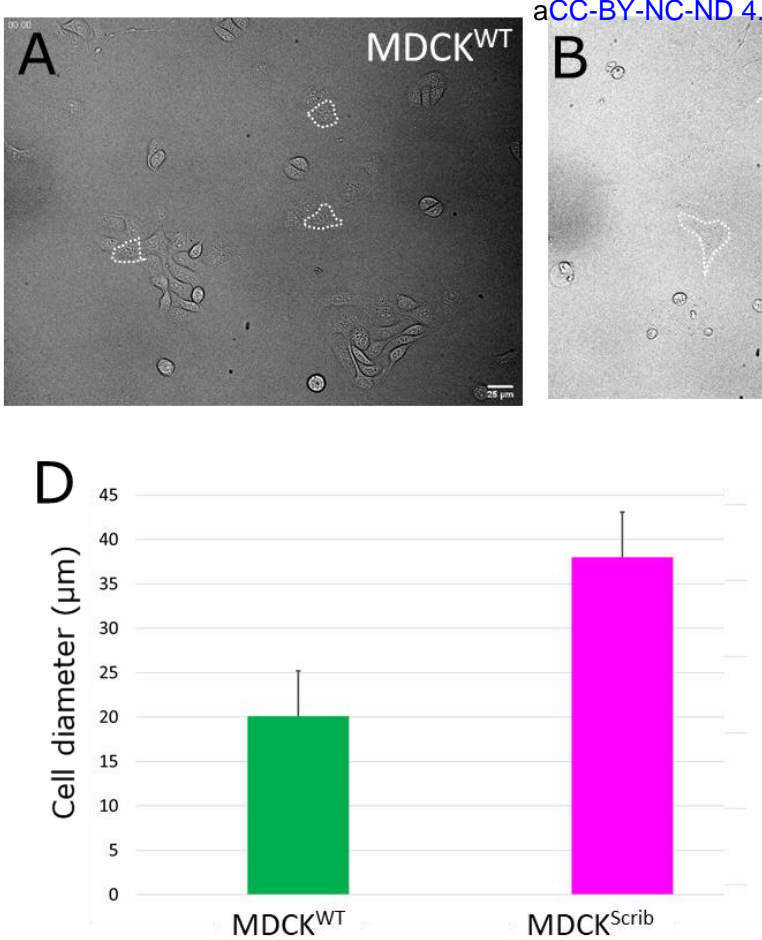
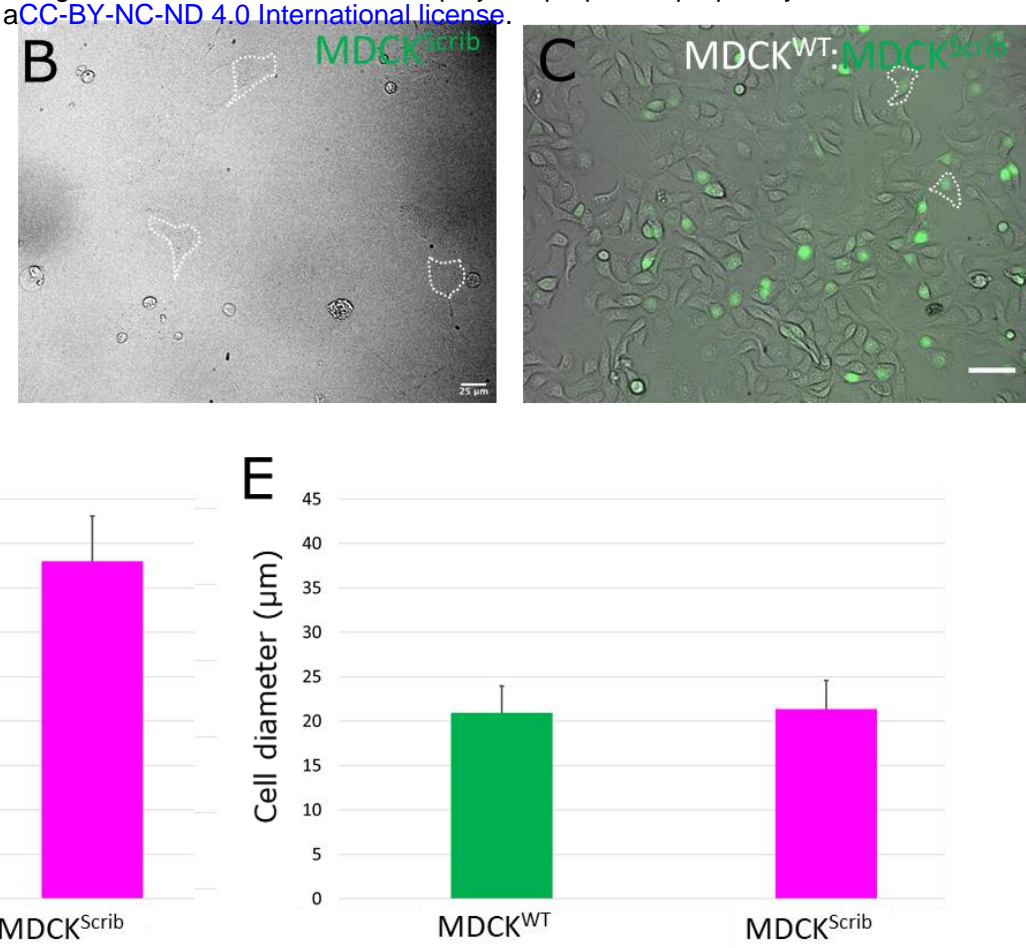

FIG S5. Cell area in pure and mixed populations prior to confluence. Brightfield images of isolated winner cells (A) and loser cells $(\mathbf{B})$ in pure populations. (A-B) Scale bars $=25 \mu \mathrm{m}$. Representative cell areas are outlined in dashed white lines. (C) Brightfield image of winner cells and loser cells in mixed populations. Loser cells are indicated by their green nuclei acquired using H2B-GFP fluorescence. Representative loser cells are outlined in dashed white lines. Scale bar $=50 \mu \mathrm{m}$. (D) Effective cell diameter for $\mathrm{MDCK}^{\mathrm{WT}}$ and $\mathrm{MDCK}^{\text {Scrib }}$ cells in pure populations. (E) Effective cell diameter for $\mathrm{MDCK}^{\mathrm{WT}}$ and $\mathrm{MDCK}^{\mathrm{Scrib}}$ cells in mixed populations. 
bioRxiv preprint doi: https://doi.org/10.1101/729731; this version posted July 13, 2020. The copyright holder for this preprint (which was not certified by peer review) is the author/funder, who has granted bioRxiv a license to display the preprint in perpetuity. It is made available under

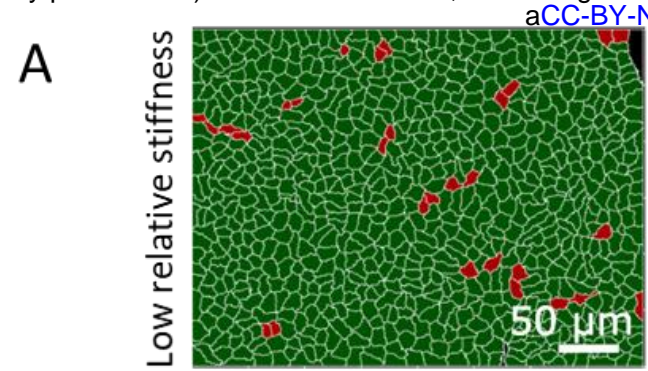

Time $=50 \mathrm{~h}$

(Confluency)

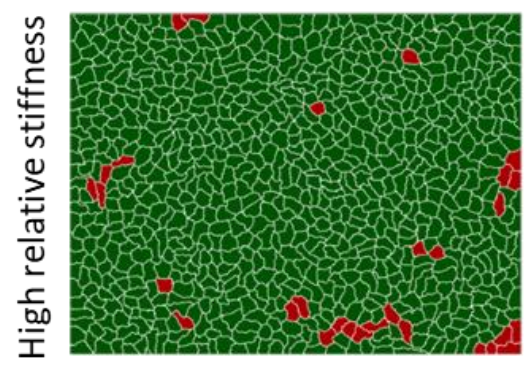

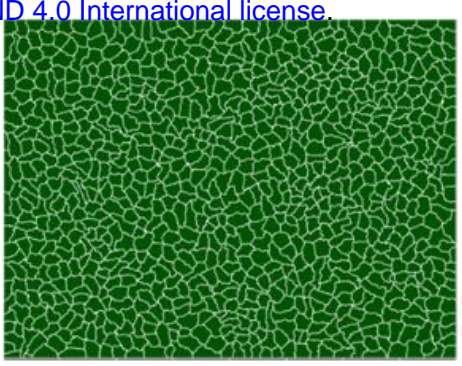

Time $=80 \mathrm{~h}$

(Post-confluency)

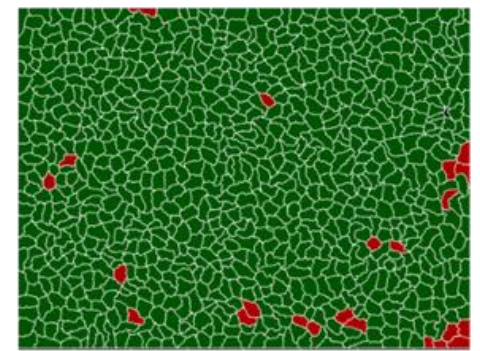

$\mathrm{C}$

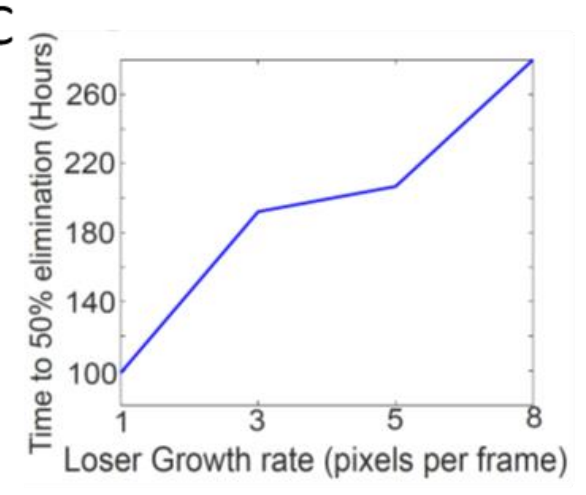

$\mathrm{E}$

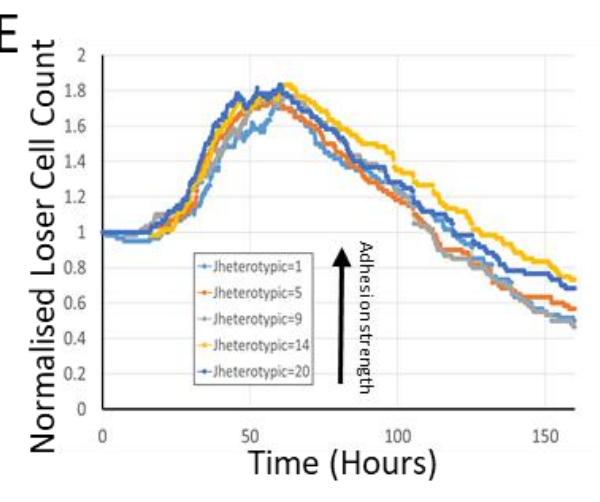

Figure S6: Effect of simulation parameters on mechanical competition. (A) Simulation snapshots of a competition initiated with $90 \%$ winner cells (green) and $10 \%$ loser cells (red). Top row: Population evolution for a low loser relative stiffness $(\Lambda=0.3)$. Bottom row: Population evolution for a high loser relative stiffness $(\Lambda=2)$. (B) Sidedness of cells post confluency for mechanical competition shown in Fig 5A. The curves indicate the proportion of cells as a function of number of neighbours. The green curve corresponds to winner cells in experiments, the blue to winner cells in simulations, the purple to loser cells in experiments and the black to loser cells in simulations. (C) Time to 50\% elimination of loser cells in mechanical competition as a function of loser growth rate. Winner cell growth rate was set to 6.0. (D) Normalised loser cell count in mechanical competition as a function of time for different values of loser cell growth rate. Winner cell growth rate was set to 6.0. (E) Evolution

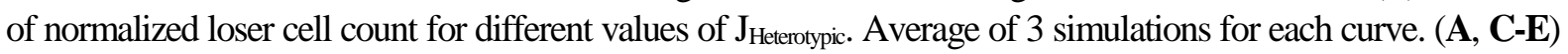
Parameters used for the simulations in this figure are in Table S2. 

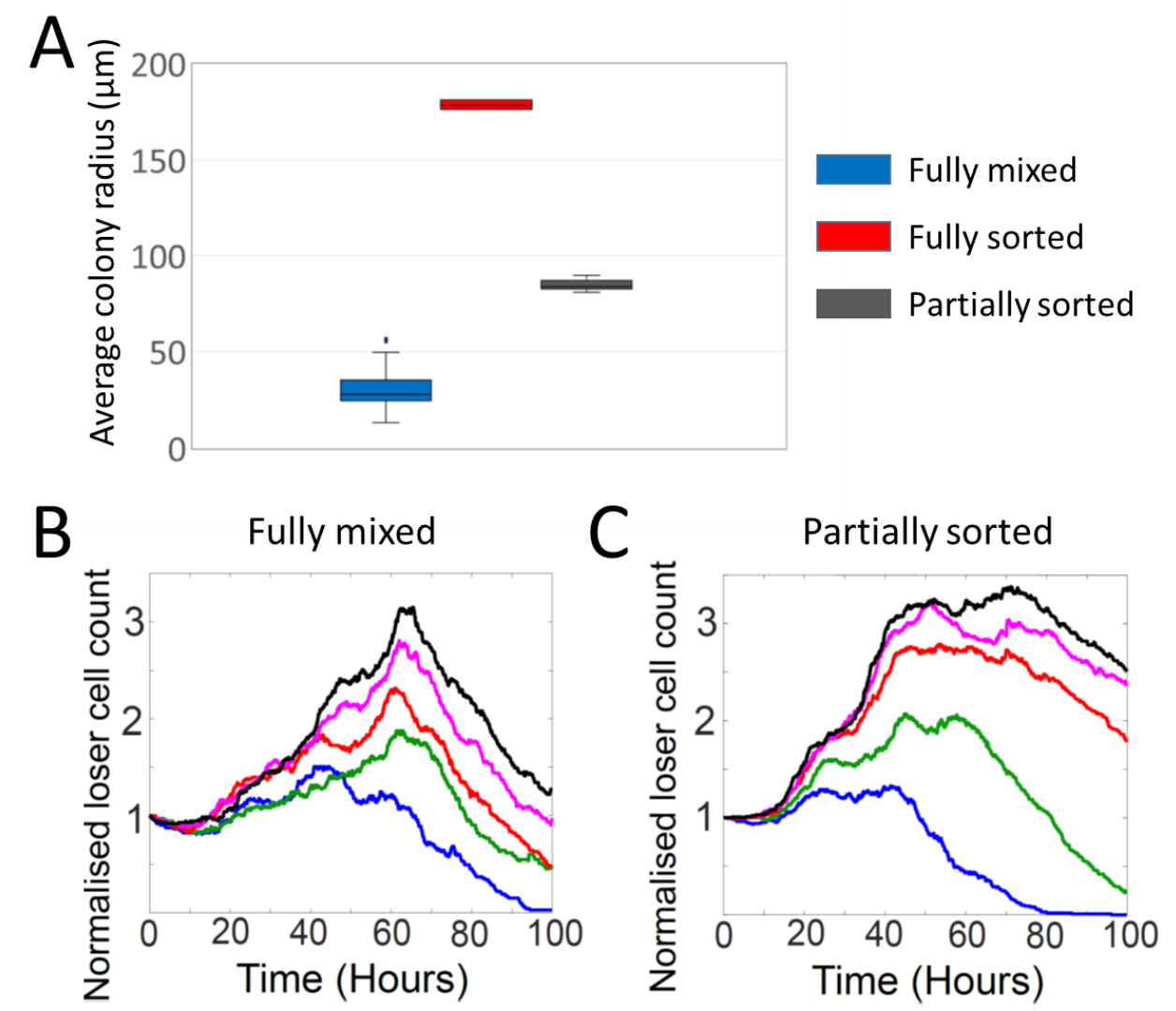

D
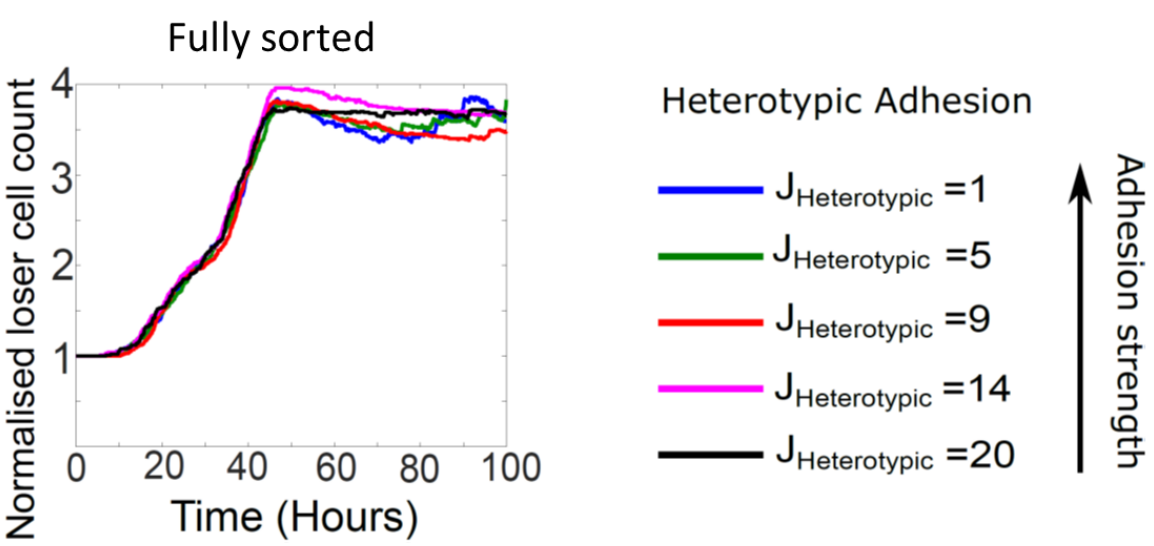

Fig S7: Colony radius and heterotypic adhesion influence the outcome of competition in biochemical competition. (A) Average loser cell colony radius at confluence for different seeding conditions. Data from three different simulations for each condition. (B-D) Heterotypic adhesion was varied from $J_{\text {Heterotypic }}=1$ to 20 . The colour code is given in the bottom right corner of the figure. (B) Normalised loser cell counts for different values of heterotypic adhesion between winner and loser cells starting from a fully mixed configuration (Fig 7A). (C) Normalised loser cell counts for different values of heterotypic adhesion between winner and loser cells starting from a partially sorted configuration (Fig 7B). (D) Normalised loser cell counts for different values of heterotypic adhesion between winner and loser cells starting from a fully sorted configuration (Fig 7C). (B-D) In our simulations, the heterotypic adhesion energy $\mathrm{J}_{\text {Heterotypic }}=1$ is the most adhesive, and $\mathrm{J}_{\text {Heterotypic }}=20$ is the least adhesive. Homotypic adhesion energy is fixed to $\mathrm{J}_{\text {Homotypic }}=8$. Parameters used for the simulations in this figure are in Table S3. 
bioRxiv preprint doi: https://doi.org/10.1101/729731; this version posted July 13, 2020. The copyright holder for this preprint (which was not certified by peer review) is the author/funder, who has granted bioRxiv a license to display the preprint in perpetuity. It is made available under
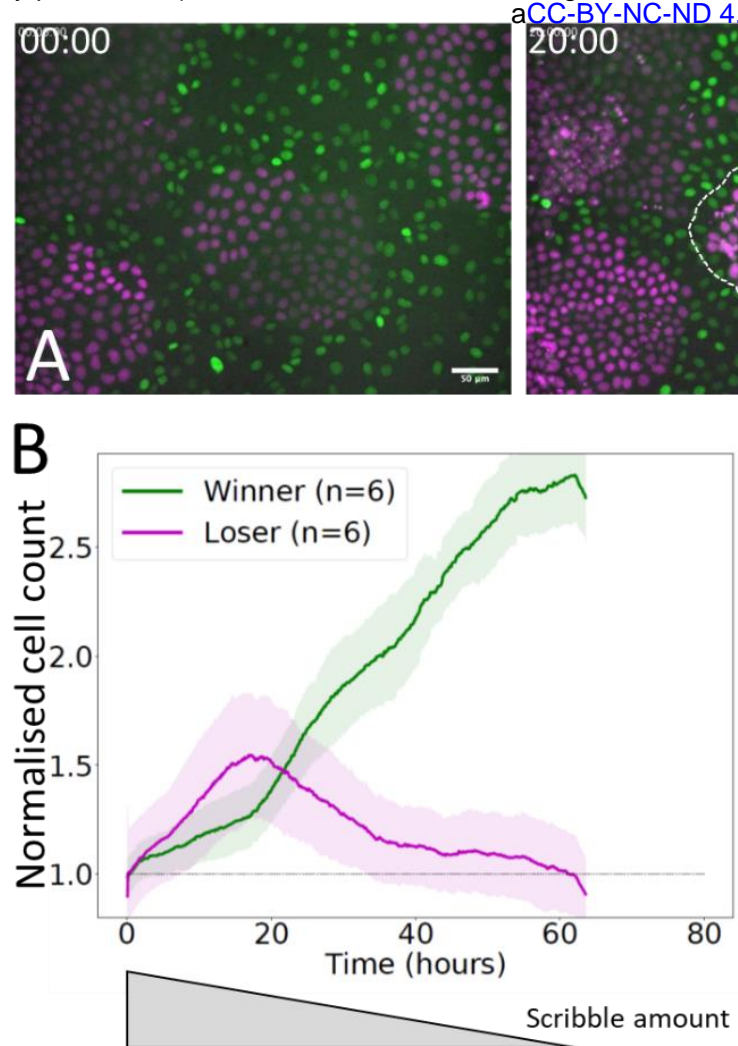
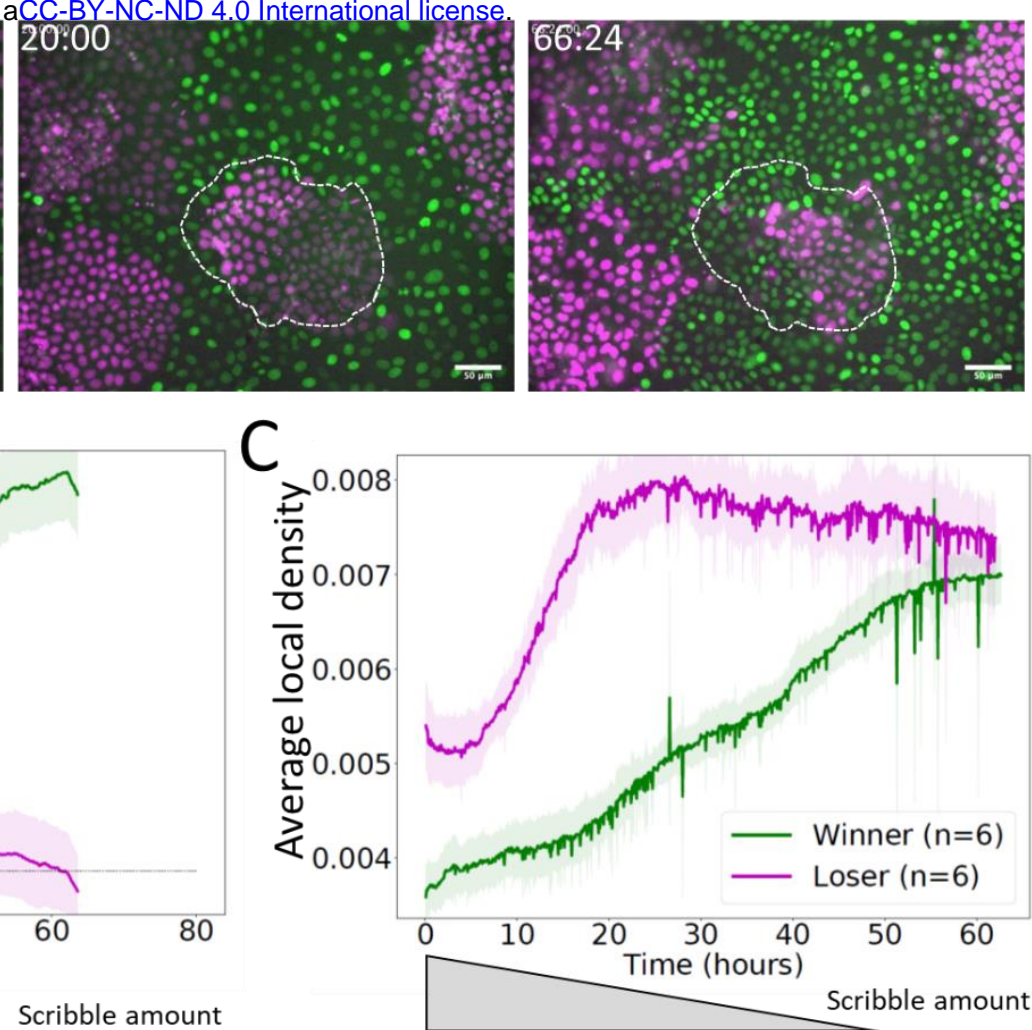

Figure S8: Mechanical competition experiments in partially sorted starting conditions. A. Experimental snapshots of a mechanical competition initiated with MDCK $^{\text {Scrib }}$ (losers, magenta) surrounded by $\mathrm{MDCK}^{\mathrm{WT}}$ cells (winners, green) in a partially sorted configuration. Dashed white lines indicate the outline of one colony at the onset of competition at $\mathrm{t}=0 \mathrm{~h}$. Silencing of Scribble was induced $24 \mathrm{~h}$ before the start of imaging and the amount of protein decreases progressively over the course of the experiment [19]. Scale bar $25 \mu \mathrm{m}$. Time is indicated in hours and minutes in the top left corner of each snapshot. B. Normalised cell count for winners (green) and losers (magenta) in a competition starting from a partially sorted configuration. C. Average local density for winner and loser cells in a competition starting from a partially sorted configuration. (B-C) Solid lines indicate the average of 6 experiments. The shaded area indicates the standard deviation. An approximate time course of scribble amount is depicted below the graph based on experimental data from [19]. 
bioRxiv preprint doi: https://doi.org/10.1101/729731; this version posted July 13, 2020. The copyright holder for this preprint (which was not certified by peer review) is the author/funder, who has granted bioRxiv a license to display the preprint in perpetuity. It is made available under

Supplementary Tables aCC-BY-NC-ND 4.0 International license.

Table S1: Table of default parameters for mechanical competition in Figures 3 and 5.

\begin{tabular}{|l|c|c|}
\hline Parameter (Unit) & Winners & Losers \\
\hline Initial $\mathrm{A}_{\mathrm{T}}$ at birth (pixels) & $\begin{array}{r}1800 \text { competition } \\
1800 \text { pure population }\end{array}$ & $\begin{array}{c}1800 \text { competition } \\
7000 \text { pure population }\end{array}$ \\
\hline$\Delta \mathrm{A}_{\text {tot }}$ (area added at each cell cycle, pixels) & 1800 & $1800 / 7000$ \\
\hline$\lambda$ Stiffness (Joules/Pixels ${ }^{2}$ ) & 1.0 & 0.7 \\
\hline $\mathrm{J}_{\text {Homotypic }}$ (Joules/pixel) & 8 & 8 \\
\hline $\mathrm{J}_{\text {Heterotypic }}$ (Joules/pixel) & 9 & 9 \\
\hline $\mathrm{J}_{\text {substrate }}$ (Joules/pixel) & 10 & 10 \\
\hline Average initial cell area at seeding (pixels) & 1800 & 500 \\
\hline Standard deviation of initial cell target area $\sigma$ (pixels) & 500 & 4.0 \\
\hline $\mathrm{G}_{-}$Growth rate (pixels per frame) & 6.0 & 0.01 \\
\hline Sensitivity to contact inhibition k (a.u.) & 0.01 & $8 \times 10^{4}$ \\
\hline $\mathrm{P}_{\text {apo_max }}$ (cell ${ }^{-1}$.frame ${ }^{-1}$ ) & $8 \times 10^{4}$ & -509.4 \\
\hline$\rho_{1 / 2}$ (pixels ${ }^{-2}$ ) & -235.8 & 0.0067 \\
\hline$\alpha$ (a.u.) & 0.0152 & \\
\hline
\end{tabular}

Parameters for the Potts model are shaded in grey. Initial conditions and computational implementation parameters are in white. Cell automaton parameters are in pink. Probability of apoptosis is implemented by a function of the form: $p_{a p o}(\rho)=\frac{p_{a p o m a x}}{\left(1+e^{-\alpha\left(\rho-\rho_{1 / 2}\right)}\right)}$. A.u. arbitrary units.

Table S2: Table of parameters for investigating the control of mechanical competition in Figure 6 and Fig S6.

\begin{tabular}{|c|c|c|}
\hline Parameter (Unit) & Winners & Losers \\
\hline Initial $A_{T}$ at birth (pixels) & 1800 & 1800 \\
\hline$\Delta \mathrm{A}_{\text {tot }}$ (area added at each cell cycle, pixels) & 1800 & 1800 \\
\hline$\lambda$ Stiffness (Joules/Pixels ${ }^{2}$ ) & 1.0 & Variable (0.1-2.0) or 0.9 \\
\hline $\mathrm{J}_{\text {Homotypic }}$ (Joules/pixel) & 8 & 8 \\
\hline $\mathrm{J}_{\text {Heterotypic }}(\mathrm{Joules} /$ pixel$)$ & 9 & Variable (4-12) or 9 \\
\hline $\mathrm{J}_{\text {substrate }}($ Joules/pixel) & 10 & 10 \\
\hline Average initial cell area at seeding (pixels) & 1800 & 1800 \\
\hline Standard deviation of initial cell area $\sigma$ (pixels) & 500 & 500 \\
\hline G-Growth rate (pixels per frame) & 6.0 & Variable (1.0-8.0) or 3.5 \\
\hline Sensitivity to contact inhibition k (a.u.) & Variable $\left(10^{-4}-1.0\right)$ & 0.01 \\
\hline$P_{\text {apo_max }}\left(\right.$ cell $^{-1}$. rrame $\left.^{-1}\right)$ & $8 \times 10^{4}$ & $8 \times 10^{4}$ \\
\hline$\rho_{1 / 2}\left(\right.$ pixels $\left.^{-2}\right)$ & -235.8 & -509.4 \\
\hline$\alpha$ (a.u.) & 0.0152 & 0.0067 \\
\hline
\end{tabular}


bioRxiv preprint doi: https://doi.org/10.1101/729731; this version posted July 13, 2020. The copyright holder for this preprint (which was not certified by peer review) is the author/funder, who has granted bioRxiv a license to display the preprint in perpetuity. It is made available under aCC-BY-NC-ND 4.0 International license.

Parameters for the Potts model are shaded in grey. Initial conditions and computational implementation parameters are in white. Cell automaton parameters are in pink. Parameters that were varied are indicated and the range is given in brackets. Probability of apoptosis is implemented by a function of the form: $p_{\text {apo }}(\rho)=\frac{p_{\text {apo max }}}{\left(1+e^{-\alpha\left(\rho-\rho_{1 / 2}\right)}\right)}$. A.u. arbitrary units.

Table S3: Table of parameters for investigating the control of biomechanical competition in Figure 7 and Fig S3.

\begin{tabular}{|c|c|c|}
\hline Parameter (Unit) & Winners & Losers \\
\hline Initial $A_{T}$ at birth (pixels) & 1800 & 1800 \\
\hline$\Delta \mathrm{A}_{\text {tot }}($ area added at each cell cycle, pixels $)$ & 1800 & 1800 \\
\hline$\lambda$ Stiffness (Joules/Pixels ${ }^{2}$ ) & 1.0 & 1.0 \\
\hline $\mathrm{J}_{\text {Homotypic }}($ Joules/pixel) & 8 & 8 \\
\hline $\mathrm{J}_{\text {Heterotypic }}$ (Joules/pixel) & 9 & Variable (1-20) or 9 \\
\hline $\mathrm{J}_{\text {substrate }}($ Joules/pixel) & 10 & 10 \\
\hline Average initial cell area at seeding (pixels) & 1800 & 1800 \\
\hline Standard deviation of initial cell area $\sigma$ (pixels) & 500 & 500 \\
\hline $\mathrm{G}-$ Growth rate (pixels per frame) & 6.0 & 6.0 \\
\hline Sensitivity to contact inhibition k (a.u.) & 0.01 & 0.01 \\
\hline $\mathrm{P}_{\text {apo_max }}\left(\right.$ cell $^{-1}$. frame $\left.^{-1}\right)$ & $2 \times 10^{4}$ & $10 \times 10^{4}$ \\
\hline $\mathrm{n}$ & 3 & 3 \\
\hline s & 0.5 & Variable $(0.1-0.9)$ or 0.5 \\
\hline
\end{tabular}

Parameters for the Potts model are shaded in grey. Initial conditions and computational implementation parameters are in white. Cell automaton parameters are in pink. Parameters that were varied are indicated and the range is given in brackets. Probability of apoptosis is implemented by a Hill function of the form: $p_{\text {apo }}(p)=p_{\text {apo } \max } p^{n} /\left(S^{n}+p^{n}\right)$ with $p$ the fraction of perimeter occupied by heterotypic adhesions. A.u. arbitrary units. 
bioRxiv preprint doi: https://doi.org/10.1101/729731; this version posted July 13, 2020. The copyright holder for this preprint (which was not certified by peer review) is the author/funder, who has granted bioRxiv a license to display the preprint in perpetuity. It is made available under Supplementary movies

Movie S1: Simulation of the growth of a pure winner cell epithelium (Fig. 3A).

Movie S2: Representative growth of a pure $\mathrm{MDCK}^{\mathrm{WT}}$ epithelium over 66 hours (Fig 3B). The nucleus of $\mathrm{MDCK}^{\mathrm{WT}}$ cells is labelled with H2B-GFP. Scale bar $25 \mu \mathrm{m}$.

Movie S3: Representative growth of a pure MDCK ${ }^{\text {Scrib }}$ epithelium over 79 hours (Fig. 3F-H). The nucleus of MDCK $^{\text {Scrib }}$ cells is labelled with H2B-mRFP. Scale bar $25 \mu \mathrm{m}$.

Movie S4: Simulation of mechanical competition between $90 \%$ winner cell types and $10 \%$ loser cell types for default parameters (Fig. 5A, C-D). The different shades of green represent the different generations of winner cells and the different shades of red represent the different generations of loser cells.

Movie S5: Representative competition between $90 \% \mathrm{MDCK}^{\mathrm{WT}}$ and $10 \% \mathrm{MDCK}^{\text {Scrib }}$ over 66 hours (Fig. 5B, 5C-D). MDCK $^{\mathrm{WT}}$ nuclei are marked with H2B-GFP (green) and MDCK $^{\text {Scib }}$ nuclei are marked with H2B-mRFP (magenta). Scale bar $25 \mu \mathrm{m}$.

Movie S6: Simulation of biochemical competition between 50\% winner cell types and 50\% loser cell types in an initial fully mixed configuration for a low value of the steepness $\mathrm{S}=0.1$ (Fig. S3C). Loser cells are almost completely eliminated within 120 hours.

Movie S7: Simulation of biochemical competition between $50 \%$ winner cell types and $50 \%$ loser cell types in an initial partially sorted configuration (Fig. 7B).

Movie S8: Simulation of mechanical competition between $50 \%$ winner cell types and $50 \%$ loser cell types in an initial partially sorted configuration (Fig. 7B).

Movie S9: Representative experiment of a competition between $\mathrm{MDCK}^{\mathrm{WT}}$ cells and $\mathrm{MDCK}^{\text {Scrib }}$ cells in a partially sorted initial configuration. MDCK $^{\mathrm{WT}}$ nuclei are marked with H2B-GFP (green) and MDCK $^{\text {Scrib }}$ nuclei are marked with H2B-mRFP (magenta). The movie represents 66 hours. Scale bar 50 $\mu \mathrm{m}$.

Movie S10: Simulation of biochemical competition between 50\% winner cell types and 50\% loser cell types in an initial fully sorted configuration (Fig. 7C). 